Research Article

\title{
Axial Compression Behavior of Circular Concrete-Filled High-Strength Thin-Walled Steel Tubular Columns with Out-of-Code $D / t$ Ratios
}

\author{
Jun-Xin Li, ${ }^{1,2}$ Jian-Tao Wang $\mathbb{D}^{3},{ }^{3}$ Qing Sun $\mathbb{D}^{1},{ }^{1}$ Yan-Ru Wu, ${ }^{1}$ Shi-Ming Zhou, ${ }^{4}$ \\ and Fa-Cheng Wang ${ }^{3}$ \\ ${ }^{1}$ Department of Civil Engineering, Xi'an Jiaotong University, Xi'an 710049, China \\ ${ }^{2}$ Construction \& Development Co.,Ltd. of China Construction Fourth Bureau, Xiamen 361000, China \\ ${ }^{3}$ Department of Civil Engineering, Tsinghua University, Beijing 100084, China \\ ${ }^{4}$ China Railway First Survey and Design Institute Group Co.,Ltd., Xi'an 710043, China
}

Correspondence should be addressed to Jian-Tao Wang; sdwfttw@tsinghua.edu.cn and Qing Sun; sunq@mail.xjtu.edu.cn

Received 11 May 2021; Revised 1 June 2021; Accepted 8 June 2021; Published 23 June 2021

Academic Editor: Haohui Xin

Copyright $\odot 2021$ Jun-Xin Li et al. This is an open access article distributed under the Creative Commons Attribution License, which permits unrestricted use, distribution, and reproduction in any medium, provided the original work is properly cited.

This paper systematically investigated the axial compression behavior of circular concrete-filled high-strength thin-walled steel tubular (CFHTST) columns with out-of-code diameter-to-thickness $(D / t)$ ratios. The axial compression test was first conducted to examine the failure mode, load-displacement curves, and composite mechanism effect. The finite element (FE) model was thereafter established to perform full-range analysis on the load versus displacement curve as well as the interaction behavior, where the parametric study was performed to investigate the influences of the material strengths and geometric sizes. Subsequently, the applicability of typical design methods was evaluated, and a revised equation for determining strain $\varepsilon_{s c y}$ corresponding to ultimate strength was established to assess the plastic deformation capacity of CFHTST columns. Finally, a theoretical model for calculating axial bearing capacity was derived based on unified twin-shear strength theory by considering the influence of intermediate principal stress. The research results indicate that a relatively high confine effect can be guaranteed for CFHTST columns under out-of-code $D / t$ ratios, given that the ratio $N_{u} / N_{\text {nom }}$ between the measured capacity $\left(N_{u}\right)$ and nominal crosssectional capacity $\left(N_{\text {nom }}\right)$ mainly distributes within 1.179 1.292; the full-range analysis reflects that the axial load-deformation curve can be distinguished by four various loading stages; the scope $b=0.3 \sim 0.55$ of intermediate stress coefficient is generally suggested for predicting axial strength of circular CFST columns within an error of $\pm 5 \%$. The abovementioned study can provide the meaningful design reference for the analysis and application of CFHTST columns.

\section{Introduction}

Circular concrete-filled steel tubular (CFST) columns have been gradually applied in many building structures, e.g., the ultrahigh-rise buildings, long-span bridges, urban viaducts, and heavy-load pylons due to their efficient fabrication procedure and favorable mechanical behavior in which the core concrete can prevent outer steel tube out of local buckling; meanwhile, the steel tube can confine the concrete infill into a triaxial compression state for improving the strength and ductility [1]. The steel tube also acts as the framework for bearing the self-weight of upper structure before casting core concrete, therefore making a reduced labor employed and construction cost [2]. However, using normal-strength (NS) materials and limiting the axial compression ratio too high in the practical structures usually result in large section sizes to reduce the architecture aesthetics as well as the thicker steel plates to increase the welding difficulty and decrease the welding quality $[3,4]$. Consequently, the high-strength (HS) material especially the HS steel (steel yield strength $f_{y} \geq 690 \mathrm{MPa}$ ) has gradually attracted great attention to conduct structural optimization 
for the traditional CFST columns, forming a relatively newtype CFST column, namely, the concrete-filled high-strength thin-walled steel $\left(f_{y} \geq 690 \mathrm{MPa}\right)$ tubular (CFHTST) columns $[5,6]$.

Various experiments have been conducted to investigate the axial compression behavior of circular CFST columns [7-29]. For example, Sakino et al. [10] examined the behavior of centrally loaded circular CFST columns using steel tubes of $f_{y}=262 \sim 835 \mathrm{MPa}$ and concrete of $f_{c}=25.4 \sim 85.1 \mathrm{MPa}$, and subsequently the stress-strain models for core concrete were proposed. Gupta et al. [19] investigated the behavior of circular concentrically loaded CFST columns with the $D / t$ ratios of $25 \sim 39$, indicating that the steel tube in a smaller $D / t$ ratio can provide high confinement effect to concrete infill. Han et al. [21] experimentally investigated the axial local compression behavior of thin-walled circular steel tube confined concrete stub columns with $D / t=72.8$, in which the steel yield strength was 362.9 $\mathrm{MPa}$ and the cube crushing strength $\left(f_{c u}\right)$ of concrete was $74.3 \mathrm{MPa}$, and it indicates that the bearing capacity decreases as increasing local compression area ratio. Beck et al. [22] conducted the axial compression test on circular CFST columns with the cylinder compressive strength $\left(f_{c}\right)$ of concrete in $22.5 \sim 105.45 \mathrm{MPa}$ combined with the NS steel tube $\left(f_{y}=287.33 \sim 342.95 \mathrm{MPa}\right)$, reflecting that the Canadian and European codes are able to predict mean column resistance compared with the conservative ANSI/AISC code. Abed et al. [23] examined the compressive behavior of circular CFST columns with NS materials under the $D / t$ ratios of $20 \sim 54$, in which it indicates that the underestimation of the axial capacities calculated by current design codes (e.g., EC4 and ACI 318) reduces as the $D / t$ ratio increases compared with the tested strength. Lai et al. [25] experimentally studied the compressive behavior of spiralconfined NS steel tube $\left(f_{y}=289.5 \mathrm{MPa}\right)$ infilled HS concrete $\left(f_{c}=104.5 \sim 125.3 \mathrm{MPa}\right)$, reflecting that spirals effectively improve the ultimate strength by an average percentage of $6.1 \%$. Xiong et al. [29] researched the compressive performance of circular CFST columns with ultrahigh-strength concrete up to $193.3 \mathrm{MPa}$ and NS steel of $300 \sim 428 \mathrm{MPa}$, where the ultimate bearing capacity can be achieved at a very small axial strain before the significant confinement to core concrete is induced owing to the brittleness of HS concrete.

However, the above studies mainly focus on concretefilled thick-walled steel tubular columns with NS steel; for the CFST columns, using HS steel may bring about larger $D / t$ ratios that were beyond the specific requirements of design codes, namely, the CFST columns with out-of-code $D / t$ ratios. Currently, a limited test data still exists for the out-ofcode CFHTST columns to investigate the composite mechanism induced by HS thin-walled steel tubes, resulting that the corresponding design method is not included in design standards. Compared with the thick-walled CFST columns, one urgent issue for CFHTST columns is that many design guidelines restrict the application of HS steel and impose strict limitation on the diameter-to-thickness $(D / t)$ ratio, i.e., American AISC 360-16 [30] applies to the structural steel of nominal yield strength not more than $525 \mathrm{MPa}$; European EC4 [31] and Chinese GB 50936-2014
[32] specify the steel yield strength limitation of $460 \mathrm{MPa}$. Considering the local buckling induced by the thin-walled steel tube, the aforementioned codes [30-32], respectively, stress the limitations of $D / t \leq 0.31 E_{s} / f_{y}, D / t \leq 90 \cdot 235 / f_{y}$, and $D / t \leq 135 \cdot 235 / f_{y}$, which obstructs the popularization and application of CFHTST columns. For those CFHTST columns with out-of-code $D / t$ ratios, there is still an uncertainty on the applicability of current design methods, in which the composite behavior between the core concrete and thinwalled steel tube also needs to be examined to ensure the confine effect for enhancing the ductility and bearing capacity of CFST columns.

This paper experimentally investigated the axial compression behavior of out-of-code CFHTST columns using Q690 steel, including the failure mode, axial load versus displacement curves, and compressive strength. A finite element (FE) model was established and verified to conduct full-range analysis for revealing the composite mechanism between outer steel tube and core concrete; subsequently, the parametric study was performed to examine the influence of material strengths and $D / t$ ratios. Finally, the applicability of existing design methods was reappraised, and the revised design methods were, respectively, proposed to predict peak strain $\varepsilon_{s c y}$ and the ultimate bearing capacity. Accordingly, the study mentioned in this paper can provide the meaningful design reference for the analysis and application of CFHTST columns.

\section{Experimental Investigation}

2.1. Specimen Design. As shown in Table 1, a total of 12 specimens were designed and tested under the axial loading, where all specimens were fabricated with the Q690 steel tubes in a constant thickness of $2 \mathrm{~mm}$. According to the design codes of AISC 360-16, EC4, and GB 50936-2014, the upper limitations of $D / t$ ratios are, respectively, 84,29 , and 43 for Q690 steel; hence, influence of various out-of-code D/ $t$ ratios $(70 \sim 130)$ was achieved by changing the diameters, and the tested stub CFST columns had the identical length $(L)$-to-diameter $(D)$ ratio of 3.75 . To identify the tested CFHTST columns, the notation was adopted in the form of CFST-O- $\diamond$ (e.g., CFST-140-1) where $\bigcirc$ indicates the outer diameter of steel tube and $\diamond$ represents the tested number of the same series. Two endplates with a thickness of $12 \mathrm{~mm}$ were welded on the bottom and top ends of columns, enabling the steel tube and core concrete exposed to axial loading together.

2.2. Material Properties. The coupon test was conducted to obtain the properties of Q690 steel tube, in which the yield strength $\left(f_{y}\right)$ and ultimate strength $\left(f_{u}\right)$ were, respectively, $741 \mathrm{MPa}$ and $795 \mathrm{MPa}$ and the modulus of elasticity $(E s)$ was $201500 \mathrm{MPa}$. As for the concrete infill, the mix proportion was in the ratio of cement (Portland 425): fine aggregate: coarse aggregate: water: water reducer: fly ash $=360: 693$ : $1084: 170: 13.2: 80$ (unit: $\mathrm{kg} / \mathrm{m}^{3}$ ). During the concrete casting, concrete test cubes $(150 \times 150 \times 150 \mathrm{~mm})$ were reserved and cured under the same condition as the tested 
TABLE 1: Details of the CFHTST columns.

\begin{tabular}{|c|c|c|c|c|c|c|c|c|c|}
\hline Specimen & $D(\mathrm{~mm})$ & $D / t$ & $f_{c u}(\mathrm{MPa})$ & $f_{y}(\mathrm{MPa})$ & $N_{\text {nom }}(\mathrm{kN})$ & $N_{u}(\mathrm{kN})$ & $N_{\mathrm{FE}}(\mathrm{kN})$ & $N_{u} / N_{\text {nom }}$ & $N_{\mathrm{FE}} / N_{u}$ \\
\hline CFST-140-1 & 140 & 70 & 50.3 & 741 & 1228 & 1589 & 1582 & 1.294 & 0.996 \\
\hline CFST-140-2 & 140 & 70 & 50.3 & 741 & 1228 & 1550 & 1582 & 1.262 & 1.021 \\
\hline CFST-140-3 & 140 & 70 & 50.3 & 741 & 1228 & 1555 & 1582 & 1.266 & 1.017 \\
\hline CFST-180-1 & 180 & 90 & 53.4 & 741 & 1885 & 2284 & 2409 & 1.212 & 1.055 \\
\hline CFST-180-2 & 180 & 90 & 53.4 & 741 & 1885 & 2405 & 2409 & 1.276 & 1.001 \\
\hline CFST-180-3 & 180 & 90 & 50.3 & 741 & 1809 & 2301 & 2342 & 1.272 & 1.018 \\
\hline CFST-220-1 & 220 & 110 & 53.4 & 741 & 2605 & 3227 & 3140 & 1.239 & 0.973 \\
\hline CFST-220-2 & 220 & 110 & 53.4 & 741 & 2605 & 3072 & 3140 & 1.179 & 1.022 \\
\hline CFST-220-3 & 220 & 110 & 50.3 & 741 & 2491 & 2990 & 3034 & 1.200 & 1.015 \\
\hline CFST-260-1 & 260 & 130 & 53.4 & 741 & 3435 & 4120 & 4104 & 1.199 & 0.996 \\
\hline CFST-260-2 & 260 & 130 & 53.4 & 741 & 3435 & 4302 & 4104 & 1.252 & 0.954 \\
\hline \multirow[t]{3}{*}{ CFST-260-3 } & 260 & 130 & 53.4 & 741 & 3435 & 4198 & 4104 & 1.222 & 0.978 \\
\hline & & & & & & & MV & 1.240 & 1.004 \\
\hline & & & & & & & $\mathrm{SD}$ & 0.036 & 0.027 \\
\hline
\end{tabular}

CFHTST columns, in which the concrete was poured by two batches. The average measured compressive cubic strengths $\left(f_{c u}\right)$ of concrete were $50.3 \mathrm{MPa}$ and $53.4 \mathrm{MPa}$ as shown in Table 1.

2.3. Instrumentation and Loading Procedure. The general schematic of the axial loading test is illustrated in Figures 1 and 2. In Figure 1, a compression testing machine of $5000 \mathrm{kN}$ capacity was utilized to impose axial load on CFHTST columns, and four displacement transducers were placed on the midheight of the column to measure out-of-plane deformations for avoiding overall instability failure. The axial shorting displacement of test column was automatically measured by the test machine. A total of 24 strain gauges (shown in Figure 2) divided into three tiers by the spacing of tube diameter were mounted on the tube surface where the layout of each layer was arranged in an equal interval of $45^{\circ}$ to record the longitudinal and circumferential deformation. Regarding the loading program, the hybrid load-displacement controlling method was used so that the axial compression was loaded with an increment of $10 \%$ of predicted ultimate bearing capacity $\left(N_{p}\right)$ until $0.6 N_{p}$ was reached, and subsequently the axial load was controlled by the displacement mode with a speed of $0.5 \mathrm{~mm} / \mathrm{min}$. Meanwhile, the loading speed of $2 \sim 3 \mathrm{kN} / \mathrm{s}$ was adopted in the load controlling stage for each increment. The test was terminated as the local buckling or concrete crushing obviously occurred.

2.4. Test Results and Analysis. A summary of typical failure modes is displayed in Figure 3. Generally, the obvious wrinkles (local buckling) of HS thin-walled steel tubes and severe concrete crushing can be similarly observed among tested CFHTST columns; however, a slight difference exists in the buckling distribution and concrete fracture surface, in which the failure slant angle of core concrete tends to form with the increase in diameter $(D / t=90 \sim 130)$, i.e., the angle between the slip line of crack face and longitudinal axis is approximately $45^{\circ}$ due to the reduced confine effect of thinwalled steel tube. The obtained axial load-displacement

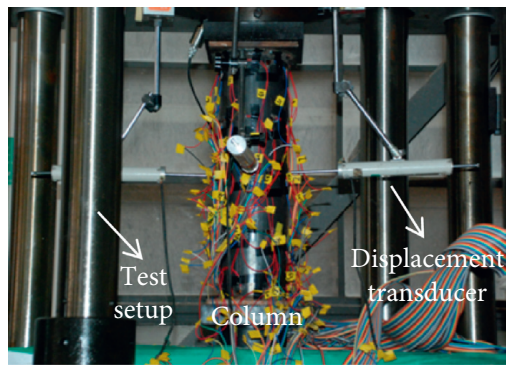

Figure 1: Test site diagram.

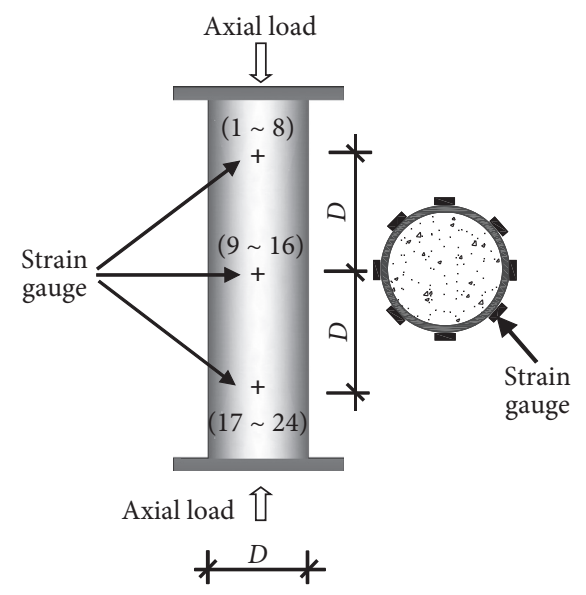

Figure 2: Schematic of measuring points.

curves are illustrated in Figure 4, for which the full-range response can be divided into the elastic, elastic-plastic, and failure stage. Comparing the columns with $D / t$ ratios of $90 \sim 130$, it can be observed that the failure stage of columns with $D / t=70$ remains a horizontal tendency without apparent degradation because of the difference of confinement coefficients $\left(\xi=\left(A_{s} f_{y} / A_{c} f_{c k}\right)\right)$ among tested columns, where $A_{s}$ and $A_{c}$ denote the cross-sectional area of steel tube and core concrete, respectively, and $f_{c k}$ is the prism strength of concrete and can be transformed through $f_{c u}$ [33]. For CFHTST columns under $D / t=70$, the calculated confinement coefficient $\xi$ is 1.14 larger than those values $(0.56 \sim 0.88)$ 


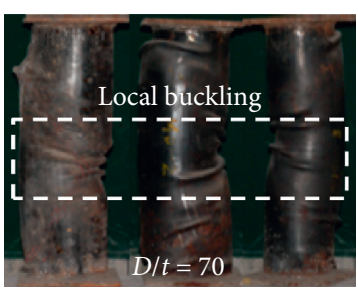

(a)

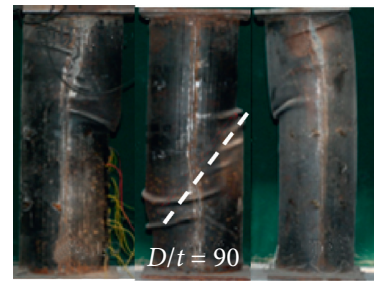

(b)

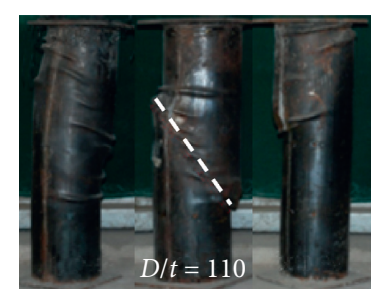

(c)

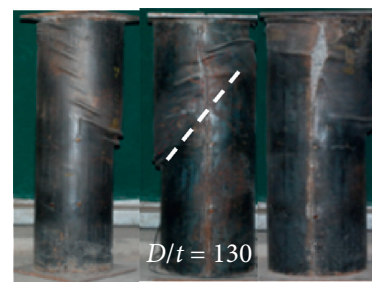

(d)

Figure 3: Failure modes.

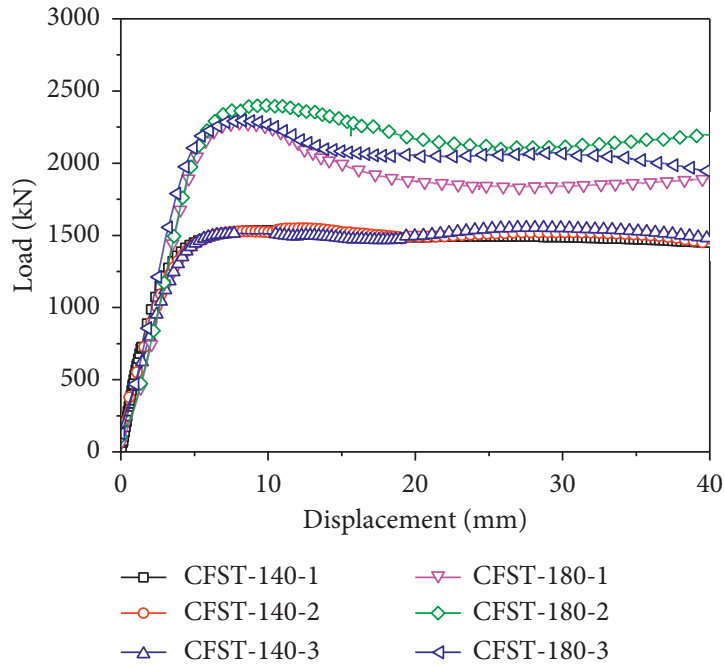

(a)

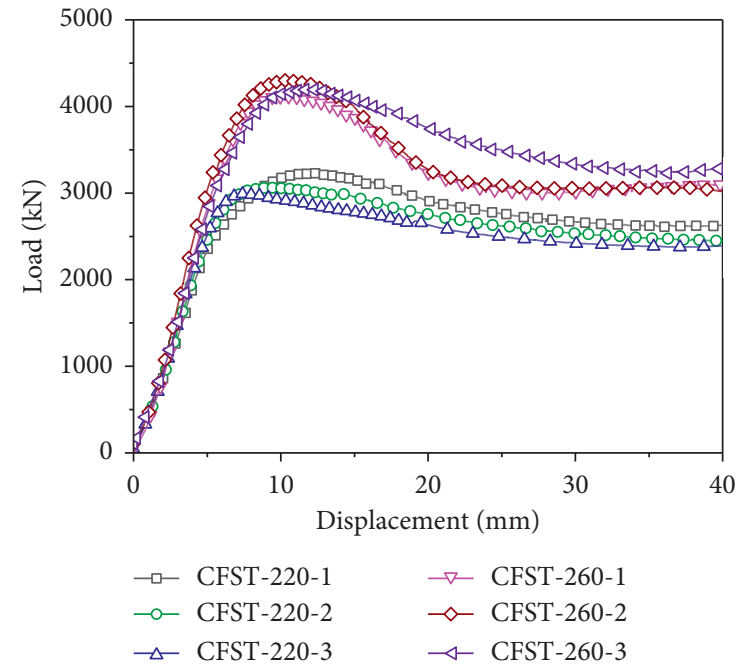

(b)

Figure 4: Axial load-displacement curves: (a) $D / t=70$ and 90; (b) $D / t=110$ and 130.

of the columns under $D / t=90 \sim 130$, reflecting the influence on composite behavior of various combinations of material and geometric parameters. As a whole, the CFHTST columns with out-of-code $D / t$ ratios do not demonstrate a sudden failure after reaching the maximum bearing capacity $\left(N_{u}\right)$, reflecting that a reasonable ductile deformation capacity can be guaranteed.

On the other hand, Figure 5 shows the measured loadstrain curves of various strain gauges, where the suffix letters of $\mathrm{L}$ and $\mathrm{C}$, respectively, indicate the longitudinal strain and circumferential strain, where the symbol FE indicates the modelling results of the numerical model that will be discussed in the following part. It can be observed that the plastic deformation of HS steel tube is fully developed beyond the yield strain, and the no obvious local buckling happens during elastic stage, reflecting an elastic-plastic buckling and failure mode. The tested bearing capacity of columns is listed in Table 1, and the nominal cross-sectional capacity $\left(N_{\text {nom }}\right)$ was calculated by $N_{\text {nom }}=A_{s} f_{y}+A_{c} f_{c}$ for comparison, where $f_{c}$ is the cylinder strength of concrete [33]. Through Table 1 , the ratio of $N_{u} / N_{\text {nom }}$ mainly distributes in the range of $1.179 \sim 1.292$ with a mean value (MV) of 1.240, demonstrating that the HS thin-walled steel tube under out-of-code can provide a relatively high confine effect to the core concrete for enhancing the bearing capacity. Therefore, from the perspective of axial bearing capacity, the limitations on $D / t$ ratios of circular CFST columns may be properly loosened using HS thin-walled steel tubes for performing structural optimization where the specific values on $D / t$ ratios should also consider the seismic demand and the cost and convenience in construction procedure.

\section{Finite Element (FE) Modelling}

To investigate the full-range axial compression behavior of circular CFHTST columns, in this part, the FE model was established and validated in ABAQUS program to reveal the composite mechanism; subsequently, the parametric study was performed to investigate the influences of key parameters on the axial compression behavior.

3.1. Establishment of FE Model. The three-dimensional eight-node hexahedral solid element C3D8R and four-node shell element S4R were, respectively, selected to simulate the core concrete and steel tube under the reduced integration mode. An elastic-plastic stress-stain relationship including five stages recommended by Han et al. [34] was adopted in the FE model to simulate the nonlinear behavior of HS steel tubes. The modulus of elasticity $\left(E_{s}\right)$ and Poisson's ratio were, respectively, taken as $206000 \mathrm{MPa}$ and 0.3 . The 

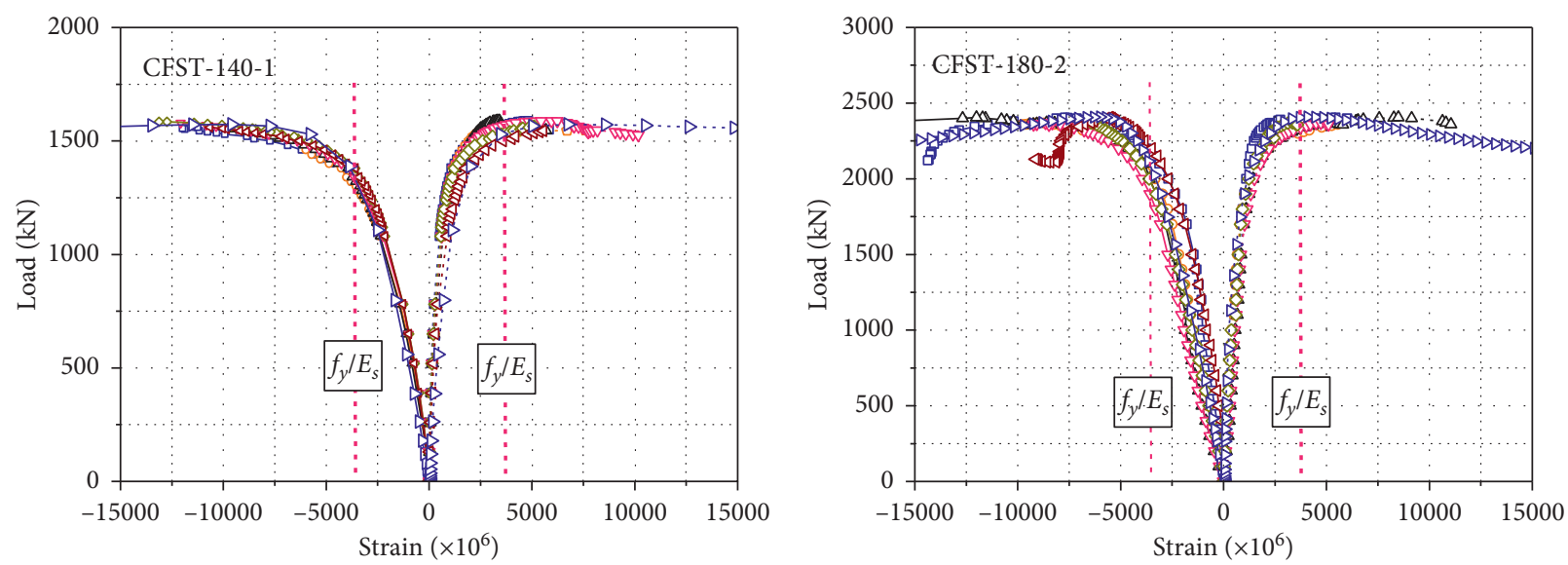

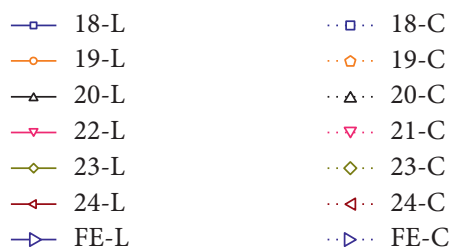

(a)

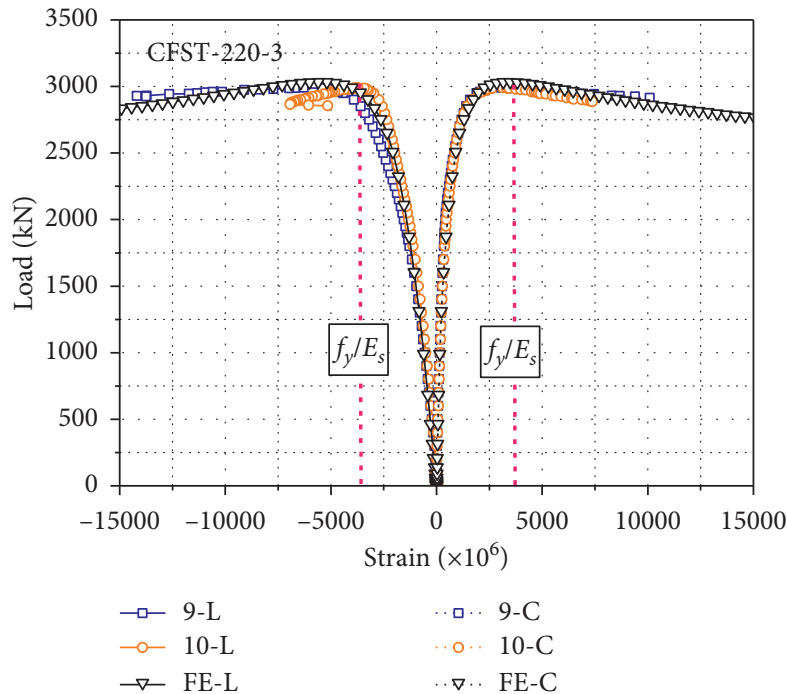

(c)

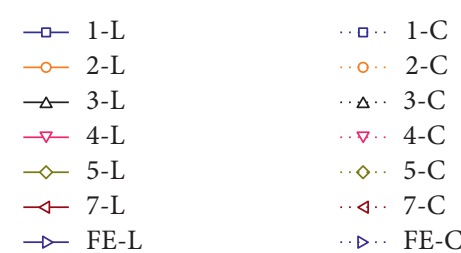

(b)

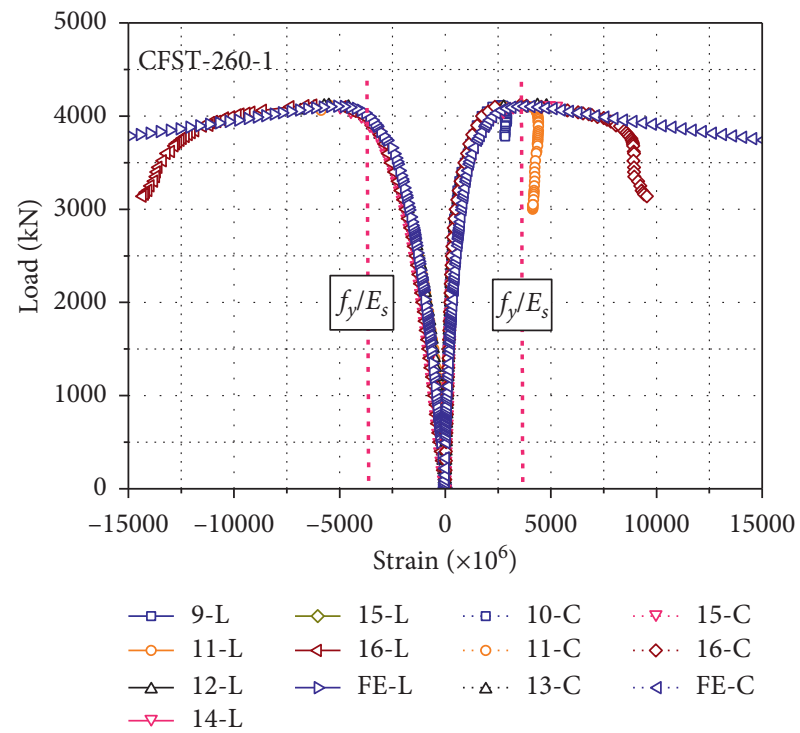

(d)

FIGURE 5: Comparison of axial load-strain curves between test and FE models: (a) CFST-140-1; (b) CFST-180-2; (c) CFST-220-3; (d) CFST260-1.

concrete damage plasticity (CDP) model offered in ABAQUS program was applied to depict the material performance [35], where the confined stress-strain relationship of concrete was adopted as follows [36]:

$$
y= \begin{cases}2 \cdot x-x^{2}, & x \leq 1, \\ \frac{x}{\beta_{0} \cdot(x-1)^{2}+x}, & x>1,\end{cases}
$$

where $x=\left(\varepsilon / \varepsilon_{0}\right)$ and $y=\left(\sigma / f_{c}\right) ; \varepsilon$ and $\sigma$ are the compressive strain and stress; $f_{c}$ is the compressive cylinder strength; $\varepsilon_{0}$ is the peak strain calculated by $\varepsilon_{0}=\varepsilon_{c}+800 \cdot \xi^{0.2} \times 10^{-6}$; and $\varepsilon_{c}=\left(1300+12.5 \cdot f_{c}\right) \times 10^{-6}$. The model parameter $\beta_{0}$ for circular CFST column is determined as

$$
\beta_{0}=\left(2.36 \times 10^{-5}\right)^{\left[0.25+(\xi-0.5)^{7}\right]} \cdot\left(f_{c}\right)^{0.5} \cdot 0.5 \geq 0.12 .
$$

The modulus of elasticity $\left(E_{c}\right)$ and Poisson's ratio for concrete can be defined as $4700 \sqrt{f_{c}}$ and 0.2 , respectively [2]. As for the tensile behavior of concrete, the fracture energybased method was utilized, and the equations for calculating the tensile strength $\left(f_{t 0}\right)$ and fracture energy $\left(G_{F}\right)$ are, respectively, as follows [37]: 


$$
\begin{aligned}
& f_{t 0}=0.26 \times\left(1.25 f_{c}\right)^{2 / 3}, \\
& G_{F}=73\left(f_{c}\right)^{0.18} .
\end{aligned}
$$

To simulate the interaction behavior between the HS thin-walled steel tube and core concrete, the Coulomb friction model and hard contact were, respectively, applied in the tangential direction and the normal direction based on the surface-to-surface contact. The relative sliding is activated when the shear stress increases up to the critical value $\left(\tau_{\text {crit }}\right)[36]$ :

$$
\begin{aligned}
\tau_{\text {crit }} & =\mu \cdot p \geq \tau_{\text {bond }}, \\
\tau_{\text {bond }} & =2.314-0.0195 \cdot \frac{D-2 t}{t} \geq 0.2\left(\mathrm{~N} / \mathrm{mm}^{2}\right),
\end{aligned}
$$

where the friction coefficient $(\mu)$ was taken as 0.6 [36]; $p$ is the contact stress of the normal direction; and $\tau_{\text {bond }}$ is the bond stress between the steel tube and concrete core that the relevant studies indicate the average bond stress for circular section is in the range of $0.2 \sim 0.4 \mathrm{MPa}$; therefore, a lower limit value of 0.2 was adopted for CFHTST columns [36]. For the HS thin-walled steel tubes, it is sensitive to the initial geometric imperfection; therefore, after the modal analysis of outer steel tube, the local imperfection amplitude $(w)$ was determined and introduced to the FE model of CFST columns as follows [30]:

$$
\frac{w}{t}=\frac{1}{16.5} \sqrt{\frac{D}{2 t}} .
$$

The mesh convergence analysis was conducted to determine an appropriate mesh density. Along the circumference, 24 elements were divided for the columns with diameters of $140 \mathrm{~mm}$ and $180 \mathrm{~mm}$, and the corresponding elements in columns with diameters of $220 \mathrm{~mm}, 260 \mathrm{~mm}$, and $300 \mathrm{~mm}$ were, respectively, set to the equal parts of 28 , 32 , and 38; additionally, the element size in the axial direction was maintained as a 1 (length) : 1 (width) scale. The fixed boundary condition was used at the column base, and an axial compression loaded by the displacement-controlled method was applied on the column top of which only the axial displacement freedom was allowed. The Newton-Raphson solving method was utilized to analyze the nonlinear behavior.

3.2. Validation of FE Model. The established FE models for CFHTST columns were validated in terms of the full-range load versus strain curve, failure mode, and ultimate bearing capacity. Figure 5 displays the validation result of full-range load versus strain curves of typical columns, in which it can be observed that the calculated curves of FE models agree well with the test curves in the initial stiffness, ultimate bearing capacity, and post-peak behavior. The suffix letters of $\mathrm{L}$ and $\mathrm{C}$, respectively, indicate the longitudinal strain and circumferential strain. The typical failure mode was compared between the simulation and test (Figure 6), from which the local buckling of the FE model matches well with test result. As for the axial bearing capacity shown in Table 1,

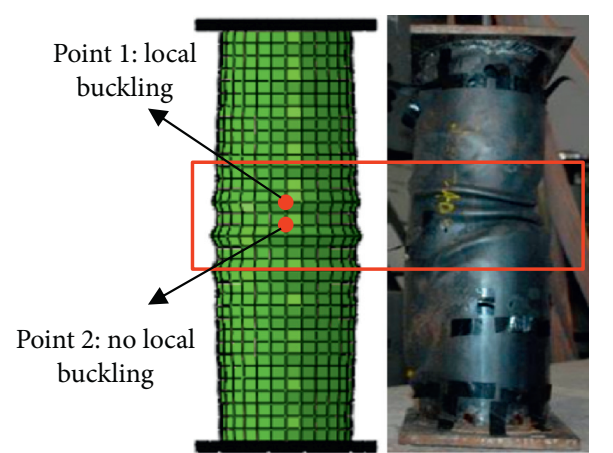

Figure 6: Failure modes of the FE model and test.

the ultimate strength $\left(N_{\mathrm{FE}}\right)$ from the FE model displays a mean value (MV) and standard deviation (SD) of 1.004 and 0.027 in the ratio $N_{\mathrm{FE}} / N_{u}$, respectively, compared with the tested ultimate capacity $\left(N_{u}\right)$. Admittedly, slight difference among the comparison results inescapably exists in the buckling extent and degradation behavior of post-peak stage, which is likely ascribed to the uncertainties in the concrete property and initial imperfection. Generally, the developed FE model in this paper simulates well with the axial compression characteristics of circular CFHTST columns and can be utilized to perform further mechanism investigation.

3.3. Full-Range Analysis on Compressive Behavior. One typical specimen was utilized for the explanation of fullrange behavior and composite mechanism, where the diameter $(D)$ and thickness $(t)$ are $220 \mathrm{~mm}$ and $2 \mathrm{~mm}$, respectively; the steel yield strength $\left(f_{y}\right)$ and compressive cylinder strength of concrete $\left(f_{c}\right)$ are, respectively, $690 \mathrm{MPa}$ and $80 \mathrm{MPa}$. The column length is 3.75 times as long as the diameter $D$. As shown in Figure 7, the typical axial loaddeformation curve of CFHTST column is displayed, and the contact pressure as well as the corresponding contributions of bearing capacity carried out by steel tube and core concrete is also illustrated, where five characteristic points marked in the curve were adopted to distinguish the various performance stages as follows:

Stage 1. OA: In this stage, the steel tube and core concrete mainly show elastic response. Because of the concrete having a smaller Poisson's ratio (0.2) than that of steel (0.3), the HS thin-walled steel tube tends to show larger lateral expansion than the core concrete; subsequently, the contact pressure remains zero, reflecting the steel tube and core concrete, respectively, working in the independent state. Therefore, in Figure 8, the circumferential stress $\sigma_{\theta}$ of steel tube is almost zero, and the Von Mises stress $\sigma_{\text {Mises }}$ can be approximately equal to the axial stress $\sigma_{z}$. Point A usually indicates that the nominal axial strain reaches the deformation of $(1 / 3)\left(f_{y} / E_{s}\right)$ (e.g., a strain of $1106 \mu \varepsilon$ for Q690 steel tube); meanwhile, the axial stress of concrete increases to $47 \mathrm{MPa}$ (Figure 9). At the end of this stage, the core concrete and steel tube, respectively, 


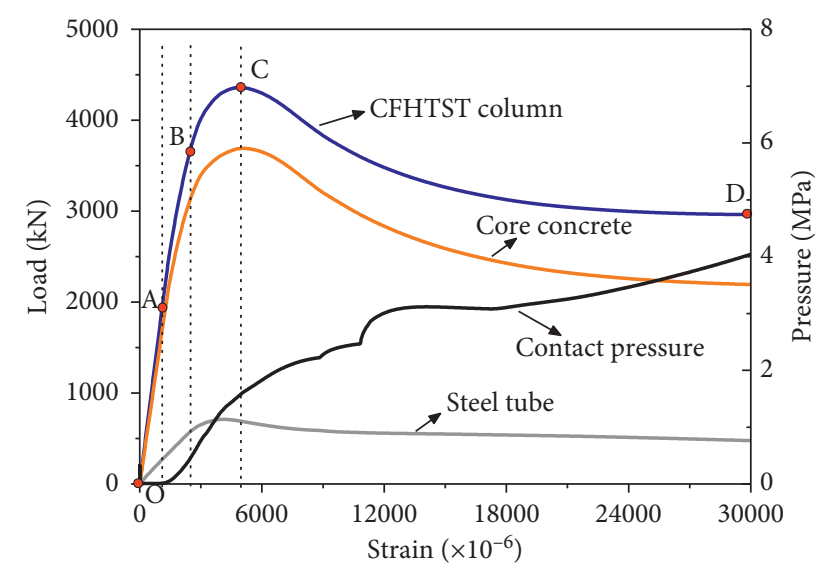

Figure 7: Analysis of full-range behavior.

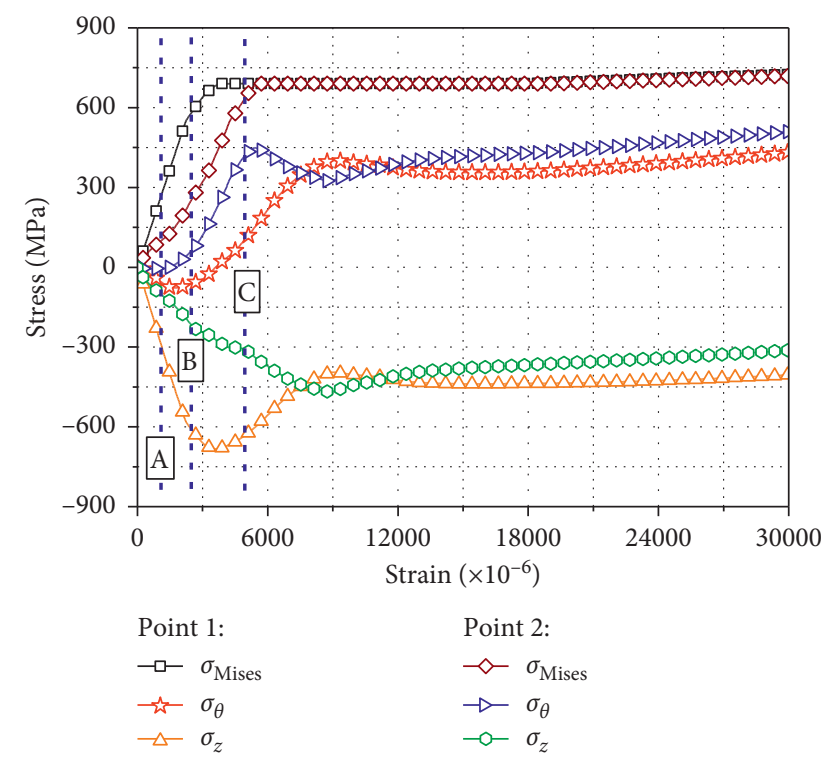

FIgURE 8: Stress development of steel tube.

contribute $87 \%$ and $13 \%$ of the compressive capacity to the whole column.

Stage 2. AB: In this stage, the contact pressure between steel tube and core concrete gradually arises, resulting in the increase in circumferential stress $\sigma_{\theta}$. Consequently, the concrete immerses in the triaxial compression accompanied by the bidirectional compression and uniaxial tension for steel tube. Point B usually indicates limit of elasticity for steel tube while the concrete can reach the stress of $87 \mathrm{MPa}$, namely, $1.088 f_{c}$ due to confinement effect (Figure 9). At point B, the steel tube and concrete, respectively, share $85 \%$ and $15 \%$ of axial strength of whole member.

Stage 3. BC: The CFHTST column enters into elasticplastic stage with obvious plastic deformation in steel and concrete while the axial compressive stiffness gradually degrades. Simultaneously, the contact pressure and circumferential stress $\sigma_{\theta}$ sharply increase. At the point $\mathrm{C}$, the column reaches the ultimate bearing capacity while the steel tube yield accompanied with local buckling, leading to a longitudinal stress degradation of buckling location, i.e., the point 1 (Figure 8). And the concrete core with a maximum stress of $105 \mathrm{MPa}$ displays a nonuniform stress distribution in radial direction. Due to the high confinement of outer HS steel tube, the concrete strength is improved to $1.313 f_{c}$ (Figure 9).

Stage 4. CD: In Figure 7, the CFHTST column exhibits a failure process as the bearing capacity of component gradually decreases accompanied by the local buckling and concrete crushing. As illustrated in Figure 10, the total response of post-peak stage mainly relies on the critical confinement coefficient $\left(\xi_{o}\right)$, in which the coefficient $\xi_{o}$ is approximately equal to 1.0 for circular CFST columns [36]. For example, in Figure 4, the tested specimens $(\xi=1.14)$ of CFST-140-1 CFST-140-3 perform an elastic perfectly plastic behavior comparing the columns with lower confinement coefficients (CFST180-1 CFST-180-3).

3.4. Parametric Study. Upon validation of the FE model, a parametric study in this section was performed to investigate the influences of key parameters on the axial compression behavior of CFHTST column, including the material strengths and geometric sizes. The detailed result of the parametric study is shown in Table 2. Influence of key parameters is discussed in following parts.

3.4.1. Effects of Concrete Strength. Figure 11 demonstrates the effects of concrete strength on the full-range axial loaddeformation curve and bearing capacity. Taking typical columns $\left(D=220 \mathrm{~mm}, t=2 \mathrm{~mm}\right.$, and $\left.f_{y}=690 \mathrm{MPa}\right)$ as examples in Figure 11(a), it indicates that the ultimate axial strength and initial tangent stiffness of CFHTST columns are significantly enhanced by increasing the concrete strength since the cross-sectional area is mainly occupied by the core concrete. The post-peak compressive behavior sharply degrades with the increase in concrete strength due to the decrease in confinement coefficient $\xi$. As for the bearing capacity in Figure 11(b), a linear increment tendency is approximately maintained with increase in concrete strength under the $D / t$ ratios of $70 \sim 150$, i.e., increasing the strength $f_{c}$ from $40 \mathrm{MPa}$ to $80 \mathrm{MPa}$ and $100 \mathrm{MPa}$, the bearing capacity, respectively, increases by $44.9 \%$ and $93.0 \%$ under $D / t=110$; however, the index $N_{\mathrm{FE}} / N_{\text {nom }}$ shown in Table 2 is weakened with the enhancement of $f_{c}$, reflecting the reduced confinement effect, i.e., the index $N_{\mathrm{FE}} / N_{\text {nom }}$ decreases by $10.29 \%$ and $14.34 \%$ for the columns with $D / t=70$ (CFST$1 \sim$ CFST-3), respectively, and in the case of $D / t=130$ (CFST10 CFST-12), those values, respectively, reduce by $8.71 \%$ and $11.81 \%$.

3.4.2. Effects of Steel Yield Strength. Figure 12 illustrates the effects of steel yield strength on the full-range behavior and bearing capacity. As shown in Figure 12(a), a slight difference exists in the initial tangent stiffness but the ultimate 


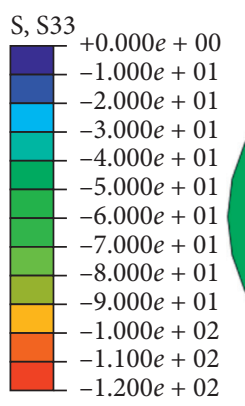

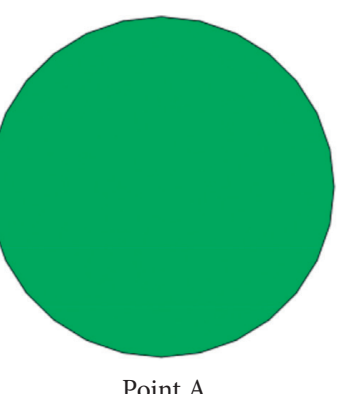

Point A

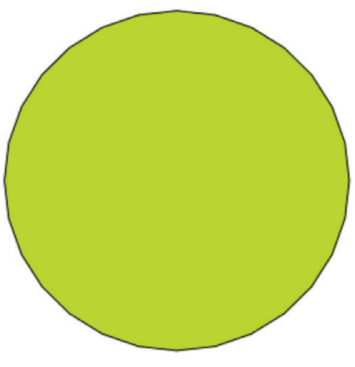

Point B

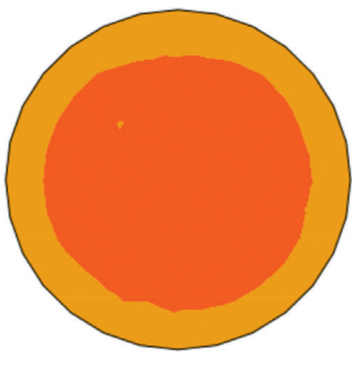

Point C

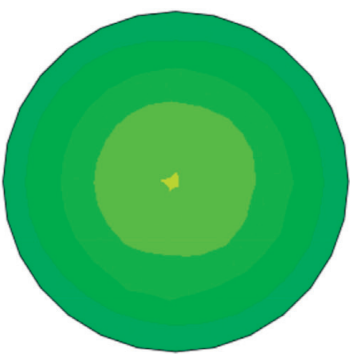

Point D

Figure 9: Stress distribution of core concrete.

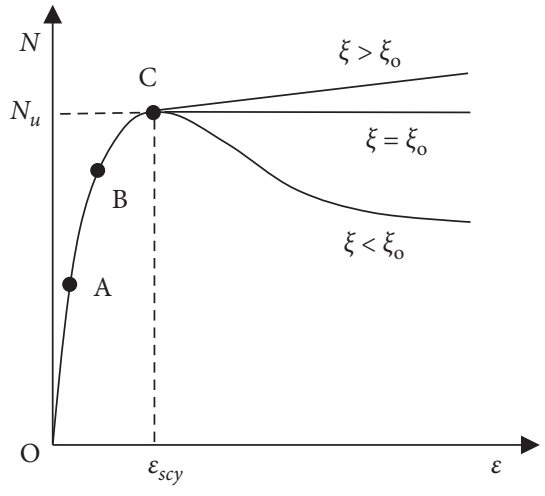

Figure 10: General types influenced by $\xi$.

strength is apparently improved while improving steel yield strength. Similar to the concrete strength, the ultimate bearing capacity in Figure 12(b) increases linearly while enhancing the strength $f_{y}$ from $460 \mathrm{MPa}$ to $890 \mathrm{MPa}$, in which the bearing capacity is, respectively, enhanced by $3.4 \%, 8.4 \%$, and $15.2 \%$ in the case of $D / t=130$. For the index $N_{\mathrm{FE}} / N_{\text {nom }}$ in Table 2, a slight increment remains within the scope of $f_{y}=460 \sim 890 \mathrm{MPa}$; for instance, $N_{\mathrm{FE}} / N_{\text {nom }}$ under $D / t=110$ (e.g., CFST-8 and CFST-22) and 130 (e.g., CFST11 and CFST-25) severally increases by $1.08 \%$ and $0.65 \%$ between $f_{y}=460 \mathrm{MPa}$ and $f_{y}=690 \mathrm{MPa}$, reflecting the tiny improvement in composite behavior due to the lower steel ratios in out-of-code $D / t$ ratios. Generally, the CFHTST columns with HS thin-walled steel tubes can remain a positive confinement effect for enhancing the composite behavior.

3.4.3. Effects of $D / t$ Ratios. Herein, the influence of $D / t$ ratio was investigated by altering the wall thickness $t$ of the steel tube as well as maintaining the diameter $D$ unchanged. Obviously, in Figure 13, the ultimate bearing capacity is decreased as increasing the thickness $t$, namely, reduces the $D / t$ ratio, i.e., the increment in $D / t$ ratio from 50 to 75 and 150 can, respectively, lead to a decrease of $16.6 \%$ and $32.6 \%$ in bearing capacity accompanied with a faster descending process of post-peak stage. Furthermore, for the columns of CFST-11, CFST-33, and CFST-34 in Table 2, the corresponding values of index $N_{\mathrm{FE}} / N_{\text {nom }}$ reduce by $4.92 \%$ and $10.41 \%$, respectively.

\section{Design Method}

4.1. Applicability of Existing Methods. To reasonably design the CFHTST columns, the applicability of existing calculation methods specified in AISC 360-16 [30], EC4 [31], and GB 50936-2014 [32] was evaluated for predicting the ultimate compression capacity. Besides, three popular design methods from literature [38-40] were also examined on the prediction accuracy of strength. As shown in Figure 14, the calculation results of abovementioned methods are displayed based on test and FE data of CFHTST columns in this paper, for which the design method in AISC 360-16 is overly conservative for predicting bearing capacity with a mean value $(\mathrm{MV})$ of 0.695 in $N_{p} / N_{u}$, where $N_{p}$ denotes the predicted bearing capacity. Inversely, the relative accuracy is, respectively, achieved by the corresponding MVs of 1.095 and 1.073 for GB 50936-2014 and EC4. The calculation methods in literature $[38,39]$ underestimate the bearing capacity of CFHTST columns with MVs of 0.846 and 0.944 compared with the MV of 1.042 for the design method in literature [40]. The difference between the above methods may ascribe to the various definitions on ultimate strength and load bearing limit state.

4.2. Strain $\varepsilon_{s c y}$ at Ultimate Strength. The strain $\varepsilon_{s c y}$ corresponding to ultimate bearing capacity generally reflects the plastic deformation capacity and composite performance of CFST columns [2, 37]. Regarding this relatively new-type circular CFHTST column, the corresponding design method is also necessary for the deformation control and limit state determination; consequently, based on the parametric study, a regressive expression displayed in equation (6) is established within the scope of $f_{c}=40 \sim 120 \mathrm{MPa}$, $f_{y}=460 \sim 890 \mathrm{MPa}$, and $D / t=50 \sim 150$, where the unit for $f_{c}$ is $\mathrm{MPa}$.

$$
\varepsilon_{s c y}=421 f_{c}^{0.5}+7224 \xi^{0.5}-3000 .
$$

As illustrated in Figure 15, the prediction result of $\varepsilon_{s c y}$ on various combinations of concrete strength $f_{c}$ and confinement coefficient $\xi$ was assessed, for which the strain $\varepsilon_{s c y}$ gradually increases as increasing $f_{c}$ and $\xi$, reflecting that the predicted result of equation (6) agrees well with the numerically determined strain $\varepsilon_{s c y}$, i.e., the strain $\varepsilon_{s c y}$ in the cases of $f_{c}=40 \mathrm{MPa}$ versus $\xi=1.02$ and $f_{c}=120 \mathrm{MPa}$ versus 
TABLE 2: Results of the parametric study.

\begin{tabular}{|c|c|c|c|c|c|c|c|c|}
\hline Specimen & $D(\mathrm{~mm})$ & $D / t$ & $L(\mathrm{~mm})$ & $f_{c}(\mathrm{MPa})$ & $f_{y}(\mathrm{MPa})$ & $N_{\text {nom }}(\mathrm{kN})$ & $N_{\mathrm{FE}}(\mathrm{kN})$ & $N_{\mathrm{FE}} / N_{\text {nom }}$ \\
\hline CFST-1 & 140 & 70 & 525 & 40 & 690 & 1179 & 1513 & 1.283 \\
\hline CFST-2 & 140 & 70 & 525 & 80 & 690 & 1760 & 2026 & 1.151 \\
\hline CFST-3 & 140 & 70 & 525 & 120 & 690 & 2341 & 2574 & 1.099 \\
\hline CFST-4 & 180 & 90 & 675 & 40 & 690 & 1745 & 2082 & 1.193 \\
\hline CFST-5 & 180 & 90 & 675 & 80 & 690 & 2718 & 3015 & 1.109 \\
\hline CFST-6 & 180 & 90 & 675 & 120 & 690 & 3691 & 3991 & 1.081 \\
\hline CFST-7 & 220 & 110 & 825 & 40 & 690 & 2411 & 3010 & 1.248 \\
\hline CFST- 8 & 220 & 110 & 825 & 80 & 690 & 3877 & 4361 & 1.125 \\
\hline CFST-9 & 220 & 110 & 825 & 120 & 690 & 5342 & 5809 & 1.087 \\
\hline CFST-10 & 260 & 130 & 975 & 40 & 690 & 3177 & 3794 & 1.194 \\
\hline CFST-11 & 260 & 130 & 975 & 80 & 690 & 5236 & 5708 & 1.090 \\
\hline CFST-12 & 260 & 130 & 975 & 120 & 690 & 7295 & 7681 & 1.053 \\
\hline CFST-13 & 300 & 150 & 1125 & 40 & 690 & 4044 & 4748 & 1.174 \\
\hline CFST-14 & 300 & 150 & 1125 & 80 & 690 & 6797 & 7428 & 1.093 \\
\hline CFST-15 & 300 & 150 & 1125 & 120 & 690 & 9550 & 10201 & 1.068 \\
\hline CFST-16 & 140 & 70 & 525 & 80 & 460 & 1561 & 1769 & 1.133 \\
\hline CFST-17 & 140 & 70 & 525 & 80 & 550 & 1639 & 1868 & 1.139 \\
\hline CFST-18 & 140 & 70 & 525 & 80 & 890 & 1934 & 2249 & 1.163 \\
\hline CFST-19 & 180 & 90 & 675 & 80 & 460 & 2461 & 2720 & 1.105 \\
\hline CFST-20 & 180 & 90 & 675 & 80 & 550 & 2561 & 2838 & 1.108 \\
\hline CFST-21 & 180 & 90 & 675 & 80 & 890 & 2942 & 3267 & 1.111 \\
\hline CFST-22 & 220 & 110 & 825 & 80 & 460 & 3562 & 3965 & 1.113 \\
\hline CFST-23 & 220 & 110 & 825 & 80 & 550 & 3685 & 4118 & 1.117 \\
\hline CFST-24 & 220 & 110 & 825 & 80 & 890 & 4151 & 4702 & 1.133 \\
\hline CFST-25 & 260 & 130 & 975 & 80 & 460 & 4863 & 5267 & 1.083 \\
\hline CFST-26 & 260 & 130 & 975 & 80 & 550 & 5009 & 5446 & 1.087 \\
\hline CFST-27 & 260 & 130 & 975 & 80 & 890 & 5560 & 6070 & 1.092 \\
\hline CFST-28 & 300 & 150 & 1125 & 80 & 460 & 6366 & 6931 & 1.089 \\
\hline CFST-29 & 300 & 150 & 1125 & 80 & 550 & 6535 & 7136 & 1.092 \\
\hline CFST-30 & 300 & 150 & 1125 & 80 & 890 & 7172 & 7814 & 1.090 \\
\hline CFST-31 & 300 & 75 & 1125 & 40 & 460 & 4390 & 5369 & 1.223 \\
\hline CFST-32 & 300 & 50 & 1125 & 40 & 460 & 5155 & 6578 & 1.276 \\
\hline CFST-33 & 300 & 75 & 1125 & 80 & 690 & 7924 & 9190 & 1.160 \\
\hline CFST-34 & 300 & 50 & 1125 & 80 & 690 & 9035 & 11022 & 1.220 \\
\hline CFST-35 & 300 & 75 & 1125 & 120 & 890 & 11346 & 12761 & 1.125 \\
\hline CFST-36 & 300 & 50 & 1125 & 120 & 890 & 12749 & 15149 & 1.188 \\
\hline
\end{tabular}

$\xi=0.42$, respectively, represents plastic deformation for various responses of post-peak stages (elastic perfectly plastic or declining behavior). Moreover, certain difference of the prediction results can be ascribed to the different definition in ultimate limit state, material nonlinearity, and initial imperfection. As a whole, the proposed expression of determining $\varepsilon_{s c y}$ can be accepted as a practical design tool to evaluate the plastic deformation capacity for circular CFHTST columns.

4.3. Theoretical Model for Compressive Strength. Many versions of strength theories have been established for structural materials, e.g., the single-shear criterion of maximum shear criterion, Huber-von Mises criterion, and two-shear criterion [41]. Generally, the yield function is expressed by the way of $F\left(\sigma_{1}, \sigma_{2}, \sigma_{3}\right)=0$, where $\sigma_{1}, \sigma_{2}$, and $\sigma_{3}$ denote the three principle stresses. Obviously, all effects of the three components of $\sigma_{1}, \sigma_{2}$, and $\sigma_{3}$ must be considered in the structural analysis, especially for the influence of intermediate principal stress $\sigma_{2}$; however, its effect on limit state is still ambiguous until the presence of unified strength theory (UST) [42], as shown in Figure 16; various limit loci can be induced due to the different contributions of intermediate principal stress, leading to an uncertain bearing capacity in ultimate limit state. Therefore, in this section, a theoretical model of compressive strength for CFHTST columns is gradually developed based on the unified twin-shear strength theory.

Through the UST, the mathematical equation is expressed as follows [42]:

$$
\begin{cases}F=\sigma_{1}-\frac{\alpha}{1+b}\left(b \sigma_{2}+\sigma_{3}\right)=\sigma_{t}, & \sigma_{2} \leq \frac{\sigma_{1}+\alpha \sigma_{3}}{1+\alpha}, \\ F^{\prime}=\frac{1}{1+b}\left(\sigma_{1}+b \sigma_{2}\right)-\alpha \sigma_{3}=\sigma_{t}, & \sigma_{2} \geq \frac{\sigma_{1}+\alpha \sigma_{3}}{1+\alpha},\end{cases}
$$

where $\alpha=\left(\sigma_{t} / \sigma_{c}\right)$ is the ratio of uniaxial tension strength $\left(\sigma_{t}\right)$ to compression strength $\left(\sigma_{c}\right)$ and $b$ is the intermediate stress coefficient that reflects the influence of intermediate principal stress. For a CFHTST column loaded in axial compression, the mechanical analysis of components is 

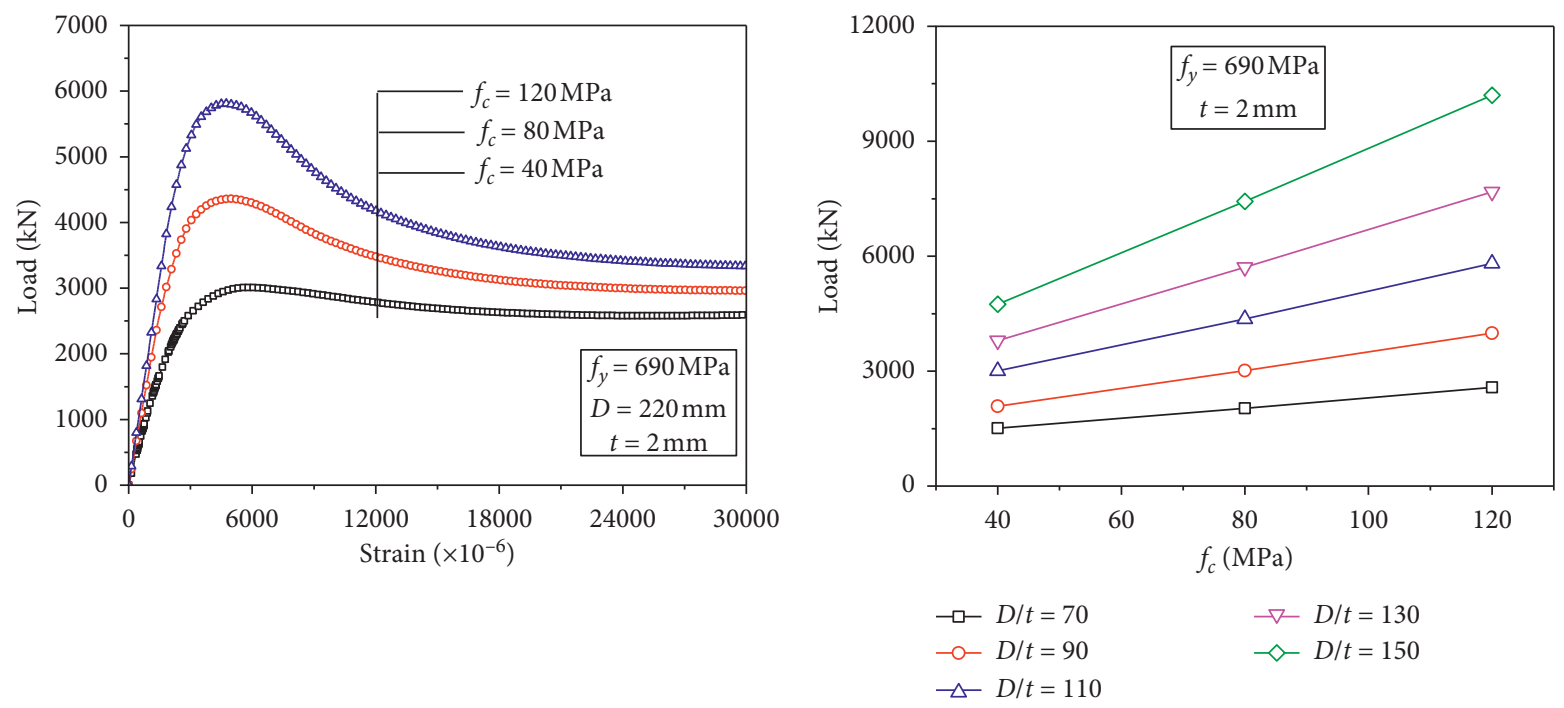

(a)

(b)

FigURE 11: Effects of concrete strength: (a) influence on full-range behavior; (b) influence on bearing capacity.

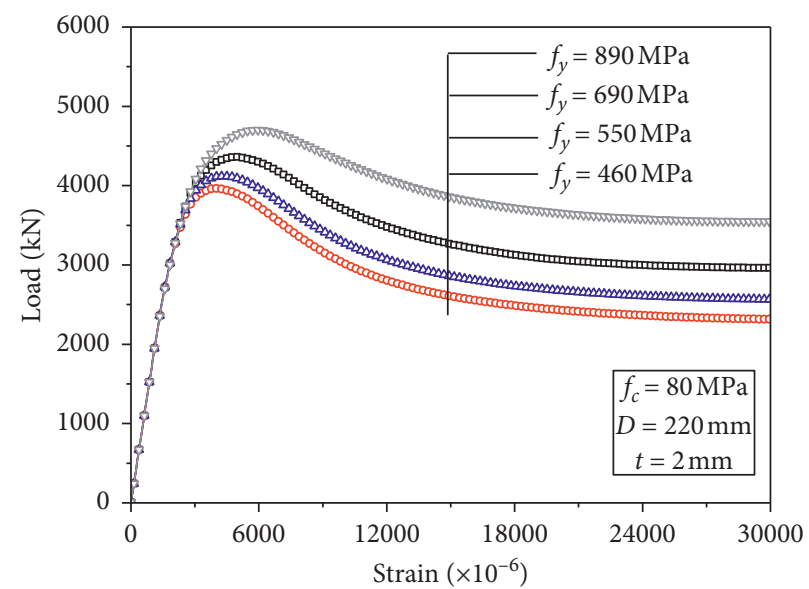

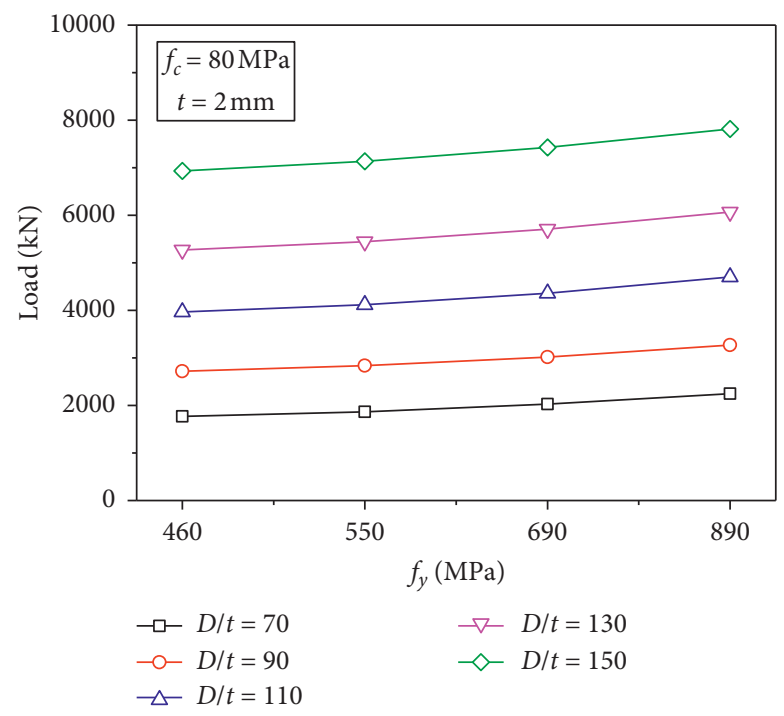

(b)

FIGURE 12: Effects of steel yield strength: (a) influence on full-range behavior; (b) influence on bearing capacity.

illustrated in Figure 17, where the core concrete is in the triaxial compression state and the steel tube suffers from the combination of bidirectional compression and circumferential tension.

Regarding the core concrete in Figure 17, the stress satisfies the condition of $0>\sigma_{1}=\sigma_{2}>\sigma_{3}$; hence, the UST in equation (7) can be defined in terms of concrete cohesion $(c)$ and internal friction angle $(\varphi)[43]$ as follows:

$$
\begin{aligned}
F^{\prime}-F & =b\left(\tau_{23}+\sigma_{23} \sin \varphi-\tau_{12}-\sigma_{12} \sin \varphi\right) \\
& =b(1-\sin \varphi)\left(\sigma_{1}-\sigma_{3}\right) \geq 0,
\end{aligned}
$$

where $\quad \tau_{23}=\left(\left(\sigma_{2}-\sigma_{3}\right) / 2\right), \quad \sigma_{23}=\left(\left(\sigma_{2}+\sigma_{3}\right) / 2\right), \quad \tau_{12}=$ $\left(\left(\sigma_{1}-\sigma_{2}\right) / 2\right)$, and $\sigma_{12}=\left(\left(\sigma_{1}+\sigma_{2}\right) / 2\right)$. Subsequently, the UST can be replaced as follows:

$F^{\prime}=\tau_{13}+b \tau_{23}+\sin \varphi\left(\sigma_{13}+b \sigma_{23}\right)=(1+b) c \sin \varphi$.

Therefore, equation (9) can be determined through $\frac{1+b}{2}\left(\sigma_{1}-\sigma_{3}\right)+\frac{1+b}{2}\left(\sigma_{1}+\sigma_{3}\right) \sin \varphi=(1+b) c \sin \varphi$.

Then, it can be further simplified to 


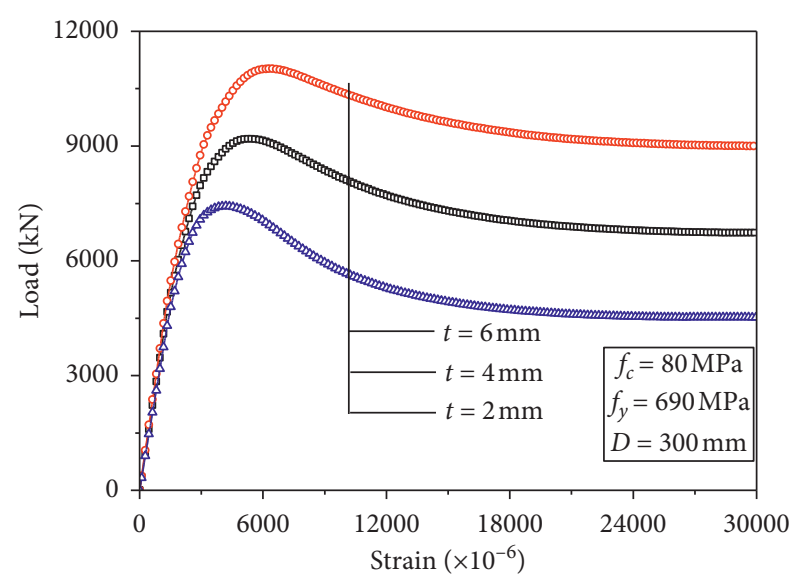

(a)

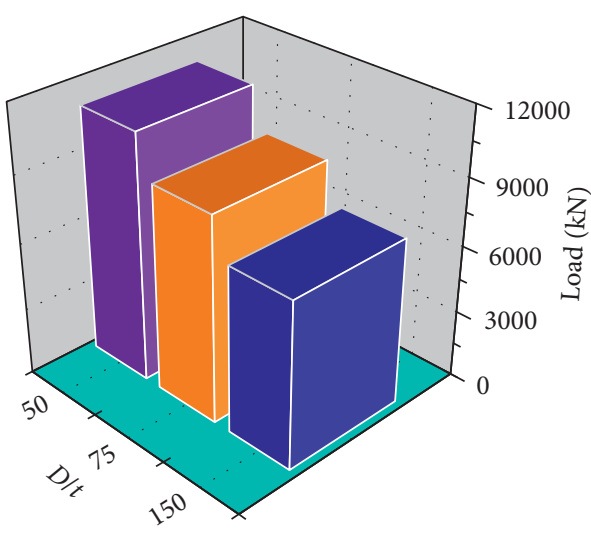

(b)

FIGURE 13: Effects of $D / t$ ratios: (a) influence on full-range behavior; (b) influence on bearing capacity.

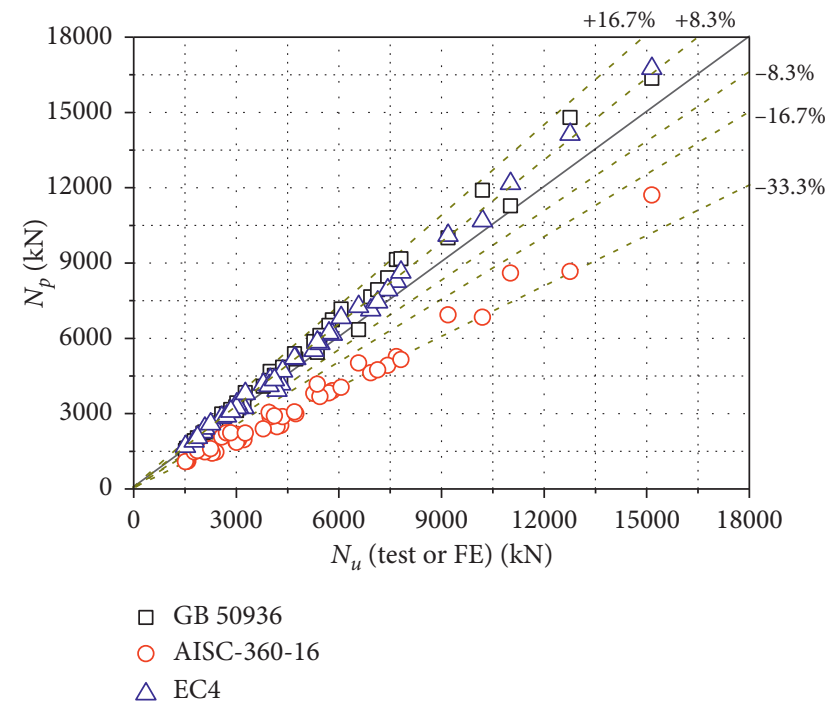

(a)

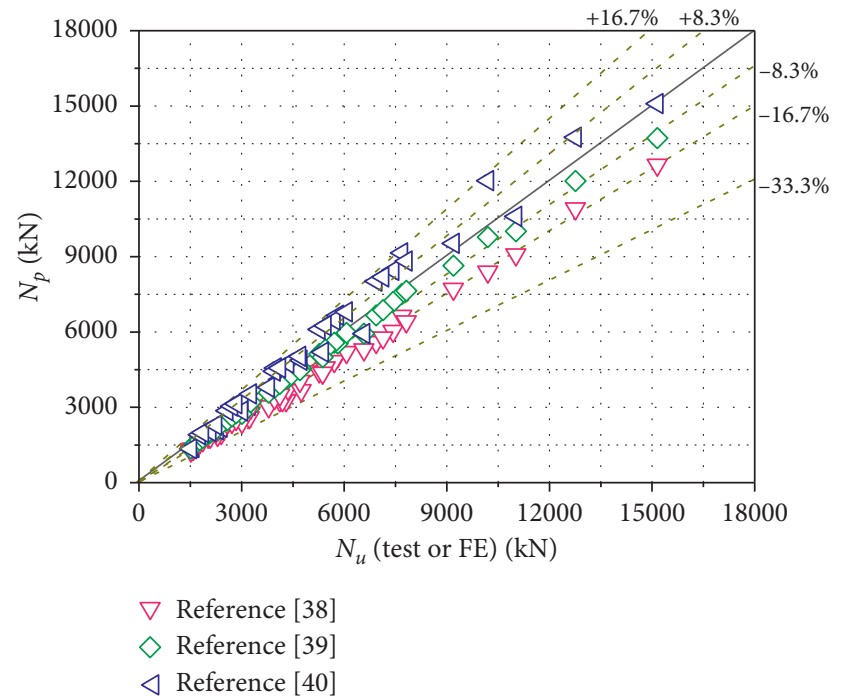

(b)

FIGURE 14: Calculation results of existing design methods: (a) methods in design codes; (b) methods in papers.

$$
-\sigma_{3}=\frac{2 c \cos \varphi}{1-\sin \varphi}-\frac{1+\sin \varphi}{1-\sin \varphi} \sigma_{1},
$$

where the subentry can be, respectively, defined as $f_{c}=$ $(2 c \cos \varphi /(1-\sin \varphi))$ and $k=((1+\sin \varphi) /(1-\sin \varphi))$ under uniaxial loading state; hence, equation (11) is translated into $\left|\sigma_{3}\right|=f_{c}+k\left|\sigma_{1}\right|$, for which $f_{c}$ is the concrete cylinder strength and $k$ is the strength enhancement factor under the triaxial compression state. The above relationship between the confining pressure $\sigma_{1}$ and axial strength $\sigma_{3}$ behaves theoretically linear, and the results of triaxial concrete compression test indicate that the enhancement factor $k=4.1$ can be approximately adopted [44]. Therefore, in this paper, the concrete strength can be defined as follows:

$$
\left|\sigma_{3}\right|=f_{c}+4.1 p
$$

Subsequently, the contribution of core concrete to the axial bearing capacity is calculated by

$$
N_{c}=\left|\sigma_{3}\right| A_{c} \text {. }
$$

From the abovementioned theory, the concrete strength under triaxial compression has no concern with the parameter $b$ because of the equal values of intermediate principal stress and minimum principal stress in circular CFST columns. Moreover, the factor $\alpha$ of steel can be approximately equal to 1 . Subsequently, for the thin-walled cylinder suffered from axial compression and radial pressure, the theoretical strength solution can be expressed as follows [45]: 


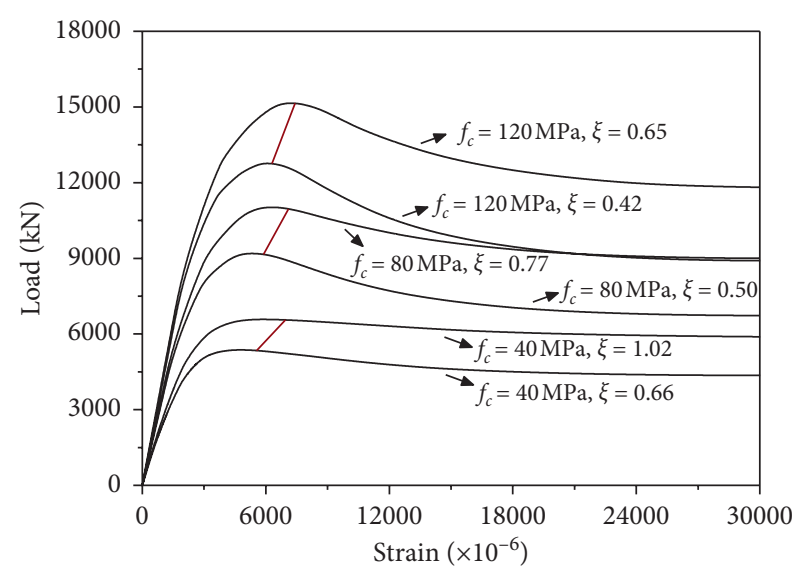

— Predicted results

Figure 15: Prediction results of $\varepsilon_{s c y}$.

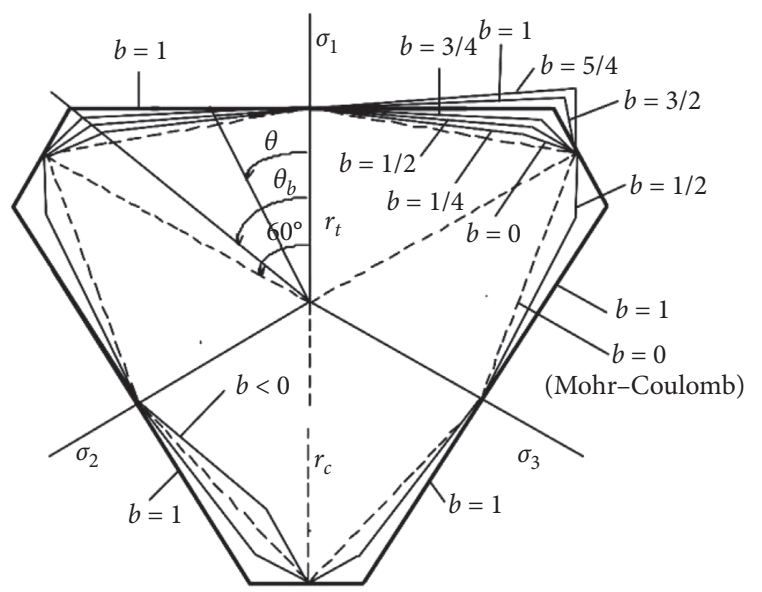

FIGURE 16: Various limit loci of unified twin-shear strength theory.

$$
\left\{\begin{array}{l}
\sigma_{1}=\sigma_{\theta}=\frac{p R}{t}, \\
\sigma_{2}=\sigma_{r}=-p, \\
\sigma_{3}=\sigma_{z}=-f_{y}+\frac{p R}{t}-\frac{p}{2},
\end{array}\right.
$$

where $R$ indicates the inside radius of steel tube and $t$ is the wall thickness. During the ultimate state of CFHTST column, the circumferential stress increases quickly than axial stress when there is no obvious initial imperfection, and the radial pressure can be obtained on the basis of equation (14) and UST in equation (7), namely,

$$
p=\frac{2 b t f_{y}}{R+2 b R+2 b t+t} .
$$

Therefore, the contribution of steel tube to axial bearing capacity can be determined as follows:

$$
N_{s}=\left|\sigma_{z}\right| A_{s}=\left(f_{y}-\frac{p R}{t}+\frac{p}{2}\right) A_{s} .
$$
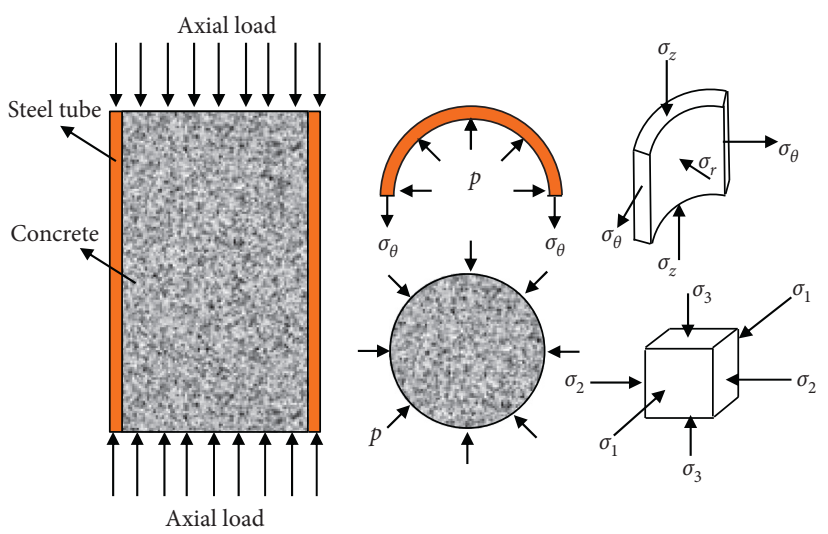

Figure 17: Mechanical analysis of CFHTST column.

Finally, the total axial capacity of CFHTST column is obtained by the superposition of equations (13) and (16), namely, $N=N_{c}+N_{s}$. Through the UST, the Huber-von Mises criterion for steel tube can be approximated by letting $b=0.5$ [42], for which it can be accepted as a primary value for predicting bearing capacities of CFHTST columns. To validate the primary model $(b=0.5)$, the test or FE data in this paper (Tables 1 and 2) were used for initiatory comparison; moreover, the test data from other literature (Table 3) including a total of 194 columns were also collected for the further model validation. The validation results of the proposed model $\left(N_{p}\right)$ are shown in Figure 18, in which a reasonable accuracy of the proposed model $(b=0.5)$ is realized by the MV $\left(N_{p} / N_{u}\right)$ of 1.065 for the CFHTST columns (Figure 18(a)); compared with the prediction results of GB 50936-2014 and EC4 in Section 4.1 (Figure 14), the proposed model performs a primary accuracy to calculate the axial bearing capacity of those CFHTST columns. Moreover, as displayed in Figure 18(b), the prediction results (242 columns) of the collected data (194 columns) and data in this paper (48 columns) generally achieve a relative precision by a MV of 1.034, reflecting that the proposed theoretical model $(b=0.5)$ can be utilized for predicting axial strength of circular CFST columns.

To investigate the influence of $b$ on axial bearing capacity, the parametric study was conducted while altering material strengths and $D / t$ ratios, as shown in Figure 19. In Figure 19(a), the predicted bearing capacity gradually increases as improving the values of $b$, in which the higher prediction results can be obtained for the HS steel (e.g., $f_{y}=690 \mathrm{MPa}$ versus $f_{y}=460 \mathrm{MPa}$ ) with value of $b$ unchanged. In Figure 19(b), increasing values of $b$ generally reduces the accuracy with a higher deviation; before $b=0.5$, the precision of $N_{p} / N_{u}$ under the same $b$ is enhanced as increasing concrete strength and vice versa, reflecting $N_{p} / N_{u}$ closing to 1. Furthermore, the influence of $b$ on various $D / t$ ratios is illustrated in Figure 19(c), where before $b=0.3$, the higher value of $N_{p} / N_{u}$ can be derived at the same $b$ when increasing $D / t$ ratios, and it gradually reduces thereafter. To examine the model accuracy on the whole database ( 242 columns) from Tables $1 \sim 3$, the prediction results of various $b$ and the average curve of $\mathrm{MV}\left(N_{p} / N_{u}\right)$ are illustrated in Figure $19(\mathrm{~d})$, 
TABLE 3: Summary of test data of circular CFST columns.

\begin{tabular}{lccccc}
\hline No. of columns & $D(\mathrm{~mm})$ & $t(\mathrm{~mm})$ & $D / t$ & $f_{c}(\mathrm{MPa})$ & $f_{y}(\mathrm{MPa})$ \\
\hline 26 & $76.5 \sim 300$ & $1.5 \sim 4.5$ & $24 \sim 100$ & $9.9 \sim 48.4$ & $232 \sim 603$ \\
18 & $121 \sim 320$ & $5 \sim 12$ & $10 \sim 46$ & $26.6 \sim 46.6$ & $249 \sim 294$ \\
6 & $100 \sim 101.8$ & $0.5 \sim 5.7$ & $18 \sim 192$ & $18 \sim 37.4$ & $244 \sim 320$ \\
10 & $159 \sim 1020$ & $5.1 \sim 13.3$ & $31 \sim 106$ & $15 \sim 46$ & $291 \sim 382$ \\
15 & $165 \sim 190$ & $0.9 \sim 2.8$ & $59 \sim 221$ & $41 \sim 108$ & $186 \sim 363$ \\
13 & $125 \sim 133$ & $1 \sim 7$ & $18 \sim 125$ & 106 & $232 \sim 429$ \\
36 & $133 \sim 168$ & $3.3 \sim 5.4$ & $25 \sim 50$ & $32.3 \sim 58.8$ & $325 \sim 392$ \\
26 & $60 \sim 250$ & $1.9 \sim 2.0$ & $32 \sim 134$ & $77.2 \sim 82$ & $282 \sim 404$ \\
31 & $101 \sim 265$ & $1.5 \sim 5.4$ & $24 \sim 68$ & $18.4 \sim 42.7$ & $265 \sim 358$ \\
13 & $101 \sim 319$ & $3.0 \sim 10.4$ & $31 \sim 34$ & $23.2 \sim 52.2$ & $335 \sim 452$ \\
\hline
\end{tabular}

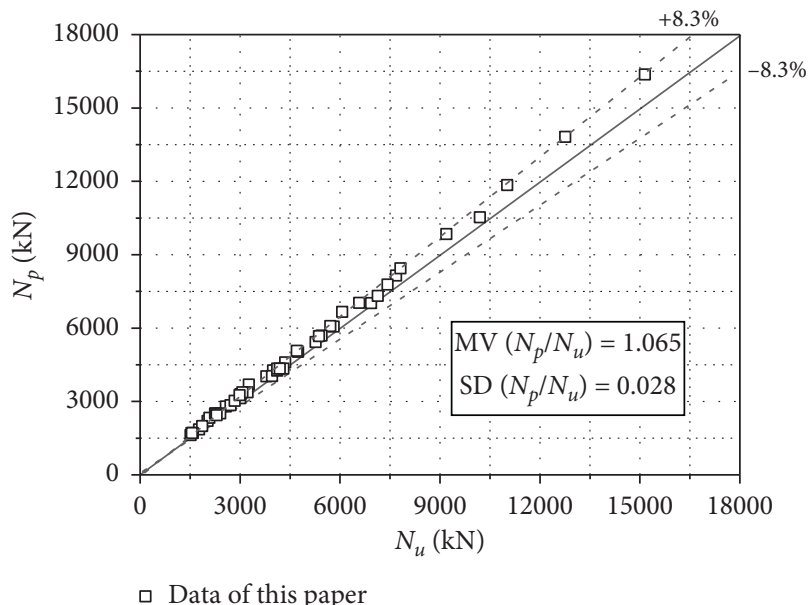

(a)

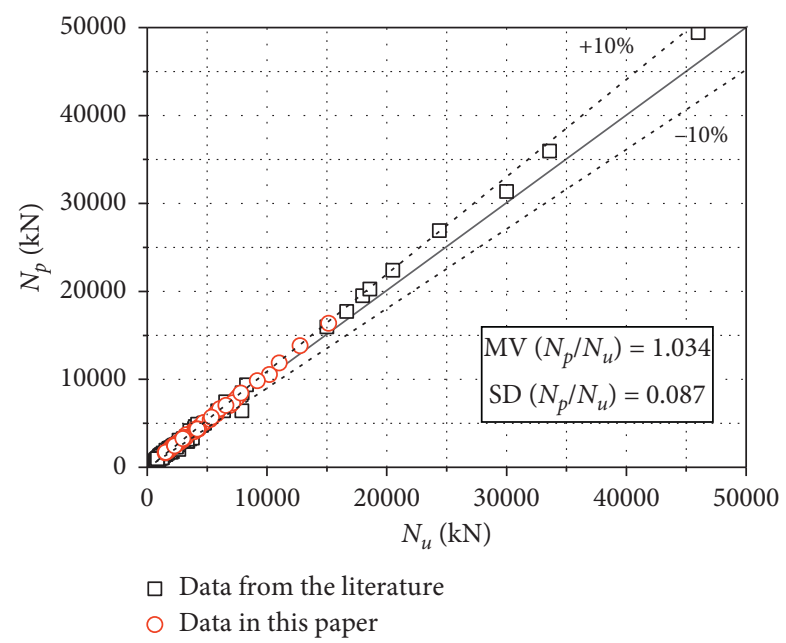

(b)

FIGURE 18: Validation of the proposed model $(b=0.5)$ : (a) prediction result for CFHTST columns; (b) prediction result of column database.

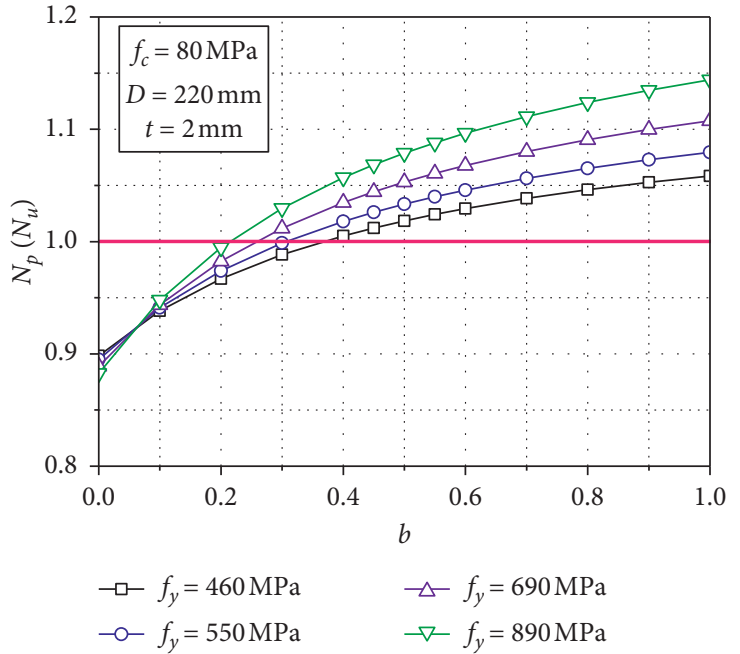

(a)

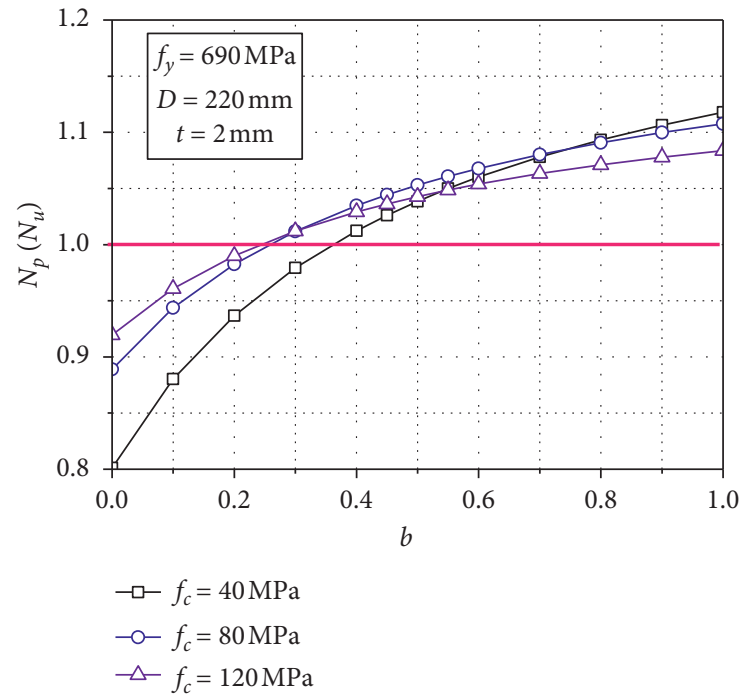

(b)

FIgURe 19: Continued. 


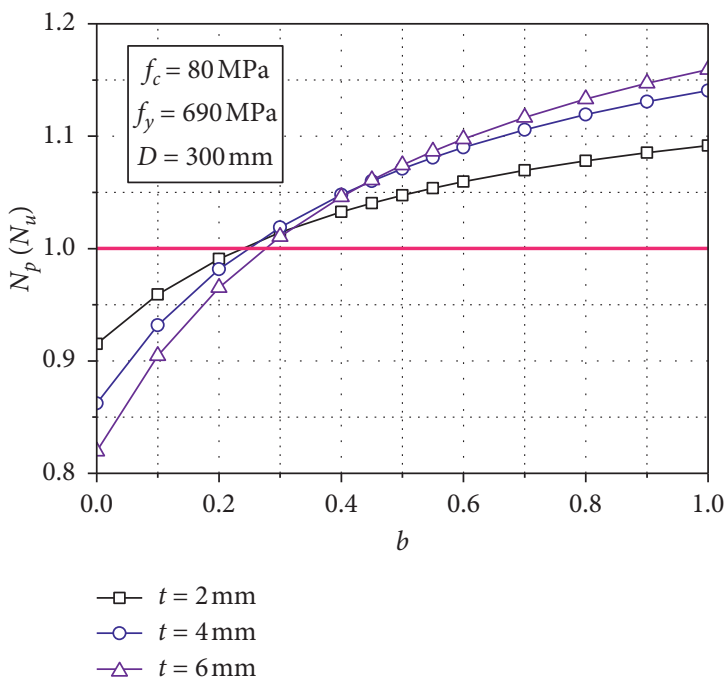

(c)

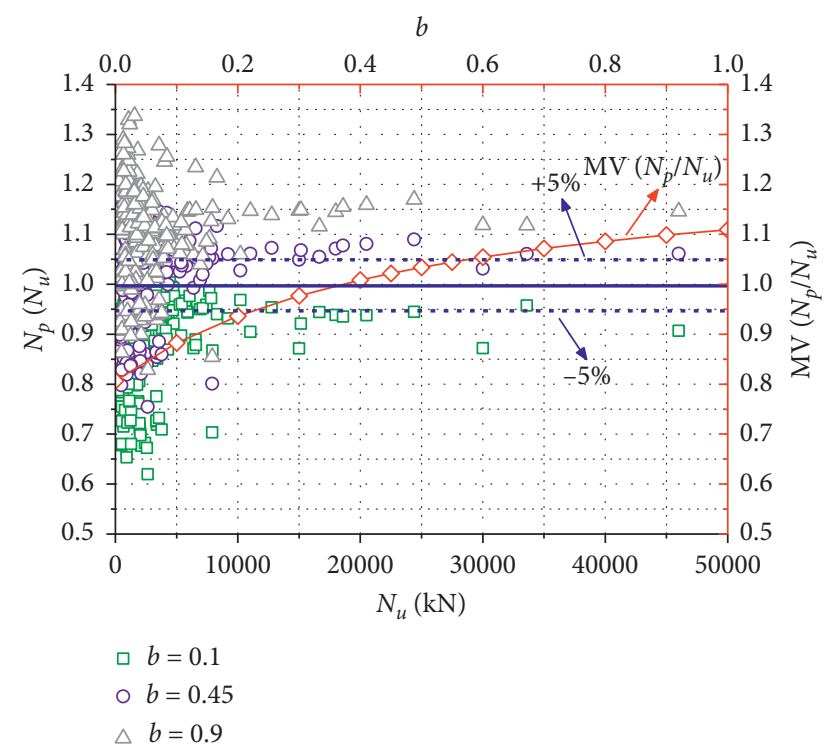

(d)

FIGURE 19: Effects of intermediate stress coefficient: (a) influence of $b$ under various $f_{y}$; (b) influence of $b$ under various $f_{c}$; (c) influence of $b$ under various $D / t$; (d) influence of $b$ on $\mathrm{MV}\left(N_{p} / N_{u}\right)$.

from which the overall predicted strength displays a higher deviation with the increase in $b$, i.e., the $\mathrm{MV}\left(N_{p} / N_{u}\right)$ for $b=0.1$ and $b=0.9$ is, respectively, 0.883 and 1.099. Regarding the average curve of $b$ versus $\mathrm{MV}\left(N_{p} / N_{u}\right)$, a reasonable accuracy can be generally achieved for $b=0.3 \sim 0.55$ within an error of $\pm 5 \%$. Therefore, the scope of intermediate stress coefficient $b=0.3 \sim 0.55$ is suggested for the predicting axial bearing capacity of circular CFST columns.

\section{Conclusions}

This paper systematically investigated the axial compression behavior of out-of-code CFHTST columns, and some valuable conclusions can be drawn within the scope of current research as follows:

(1) The tested CFHTST columns fail in a mode of severe local buckling and concrete crushing, where the angle between the slip line of crack face and longitudinal axis is approximately $45^{\circ}$ under $\mathrm{D} /$ $t=90 \sim 130$. The ratios of $N_{u} / N_{\text {nom }}$ mainly distribute within $1.179 \sim 1.292$ by a MV of 1.240 , demonstrating that the HS thin-walled steel tubes under out-of-code $D / t$ ratios can provide a relatively high confine effect to core concrete for enhancing the bearing capacity.

(2) The FE model is established for revealing composite mechanism, where the axial load-deformation curve can be distinguished by four various loading stages, and the composite action is analyzed based on the stress development and full-range interaction behavior.

(3) The applicability of typical design methods including AISC 360-16, EC4, and GB 50936-2014 is evaluated for predicting the ultimate compression capacity, where the method in AISC $360-16$ is overly conservative for predicting bearing capacity with a $\mathrm{MV}$ of 0.695 in $N_{p} / N_{u}$. Inversely, the relative accuracy is, respectively, achieved by the corresponding MVs of 1.095 and 1.073 for GB 50936-2014 and EC4.

(4) The expression that can be accepted as a practical design tool for determining strain $\varepsilon_{s c y}$ corresponding to ultimate compression strength is established and verified for evaluating the plastic deformation capacity of CFHTST columns.

(5) A theoretical model for calculating axial bearing capacity is derived and established based on the unified twin-shear strength theory by considering the influence of intermediate principal stress. The database of collected circular CFST columns is developed for preliminary model validation $(b=0.5)$ where the prediction results generally achieve a relative precision by a MV of 1.034. Subsequently, the overall predicted strength displays a higher deviation with the increase in $b$, i.e., the $\mathrm{MV}\left(N_{p} / N_{u}\right)$ of $b=0.1$ and $b=0.9$ which are, respectively, 0.883 and 1.099. The scope $b=0.3 \sim 0.55$ of intermediate stress coefficient is generally suggested for predicting axial bearing capacity of circular CFST columns within an error of $\pm 5 \%$.

\section{Data Availability}

The research data used to support the findings of this study are available from the corresponding authors upon request.

\section{Conflicts of Interest}

The authors declare that there are no conflicts of interest regarding the publication of this paper. 


\section{Authors' Contributions}

Jun-Xin Li and Jian-Tao Wang contributed equally to this paper.

\section{Acknowledgments}

The research work reported in this paper was part of the Project supported by the National Natural Science Foundation of China (nos. 51922064, 51978570, and 52008228), the Project funded by China Postdoctoral Science Foundation (no. 2020M670341), and the Technology Research \& Development Program of China Construction Fourth Bureau (no. CSCEC4B-2021-KTA-8). The financial support is gratefully acknowledged.

\section{References}

[1] L.-H. Han, W. Li, and R. Bjorhovde, "Developments and advanced applications of concrete-filled steel tubular (CFST) structures: members," Journal of Constructional Steel Research, vol. 100, pp. 211-228, 2014.

[2] J. T. Wang and F. C. Wang, "Analytical behavior of built-up square concrete-filled steel tubular columns under combined preload and axial compression," Steel and Composite Structures, vol. 38, no. 6, pp. 617-635, 2021.

[3] Y. Du, Z. Chen, Y.-B. Wang, and J. Y. Richard Liew, "Ultimate resistance behavior of rectangular concrete-filled tubular beam-columns made of high-strength steel," Journal of Constructional Steel Research, vol. 133, pp. 418-433, 2017.

[4] T.-J. Li, G.-Q. Li, S.-L. Chan, and Y.-B. Wang, "Behavior of Q690 high-strength steel columns: part 1: experimental investigation," Journal of Constructional Steel Research, vol. 123, pp. 18-30, 2016.

[5] J. Wang, Q. Sun, and J. Li, "Experimental study on seismic behavior of high-strength circular concrete-filled thin-walled steel tubular columns," Engineering Structures, vol. 182, pp. 403-415, 2019.

[6] S. Zhou, Q. Sun, and X. Wu, "Impact of $D / t$ ratio on circular concrete-filled high-strength steel tubular stub columns under axial compression," Thin-Walled Structures, vol. 132, pp. 461-474, 2018.

[7] J. Gardner and E. R. Jacobson, "Structural behaviour of concrete filled steel tubes," ACI Structural Journal, vol. 64, no. 7, pp. 404-413, 1967.

[8] G. Tang, B. Zhang, H. Zhu, and X. Shen, "Study on the fundamental structural behavior of concrete filled steel tubular columns," Journal of Building Structures, no. 1, pp. 13-31, 1982.

[9] S. Cai and Z. Jiao, "Behavior and ultimate strength of short concrete-filled steel tubular columns," Journal of Building Structures, vol. 5, no. 6, pp. 13-29, 1984.

[10] K. Sakino, M. Tomii, and K. Watanabe, "Sustaining load capacity of plain concrete stub columns confined by circular steel tube," in Proceedings of the 1985 International Speciality Conference on Concrete Filled Steel Tubular Structures, pp. 112-118, Harbin, China, 1985.

[11] L. K. Luksha and A. P. Nesterovich, "Strength testing of largediameter concrete filled steel tubular members," in Proceedings of the 3rd International Conference on Steel-Concrete Composite Structures, M. Wakabayashi, Ed., pp. 67-72pp. 67-, Fukuoka, Japan, 1991.
[12] R. Q. Bridge and M. D. O’Shea, “Australian composite code, concrete filled tubes," in Proceedings of the 1997 ASCCS Seminar, Concrete Filled Steel Tubes: A Comparison of International Codes and Practices, pp. 59-74, Innsbruck, Austria, 1997.

[13] M. D. O’Shea and R. Q. Bridge, "Local buckling of thin-walled circular steel sections with or without internal restraint," Journal of Constructional Steel Research, vol. 41, no. 2-3, pp. 137-157, 1997.

[14] K. Tan, X. Pu, and S. Cai, "Study on the mechanical properties of steel extra-high strength concrete encased in steel tubes," Journal of Building Structures, vol. 20, no. 1, pp. 10-15, 1999.

[15] S. Zhang and Y. Wang, "Failure modes of short columns of high-strength concrete-filled steel tubes," China Civil Engineering Journal, vol. 37, no. 9, pp. 1-10, 2004.

[16] K. Sakino, H. Nakahara, S. Morino, and I. Nishiyama, "Behavior of centrally loaded concrete-filled steel-tube short columns," Journal of structural engineering, vol. 130, no. 2, pp. 180-188, 2004.

[17] L.-H. Han, G.-H. Yao, and X.-L. Zhao, "Tests and calculations for hollow structural steel (HSS) stub columns filled with selfconsolidating concrete (SCC)," Journal of Constructional Steel Research, vol. 61, no. 9, pp. 1241-1269, 2005.

[18] Y.-F. Yang and L.-H. Han, "Experimental behaviour of recycled aggregate concrete filled steel tubular columns," Journal of Constructional Steel Research, vol. 62, no. 12, pp. 1310-1324, 2006.

[19] P. K. Gupta, S. M. Sarda, and M. S. Kumar, "Experimental and computational study of concrete filled steel tubular columns under axial loads," Journal of Constructional Steel Research, vol. 63, no. 2, pp. 182-193, 2007.

[20] Q. Yu, Z. Tao, and Y.-X. Wu, "Experimental behaviour of high performance concrete-filled steel tubular columns," ThinWalled Structures, vol. 46, no. 4, pp. 362-370, 2008.

[21] L.-H. Han, W. Liu, and Y.-F. Yang, "Behavior of thin walled steel tube confined concrete stub columns subjected to axial local compression," Thin-Walled Structures, vol. 46, no. 2, pp. 155-164, 2008.

[22] A. T. Beck, W. L. A. de Oliveira, S. De Nardim, and A. L. H. C. ElDebs, "Reliability-based evaluation of design code provisions for circular concrete-filled steel columns," Engineering Structures, vol. 31, no. 10, pp. 2299-2308, 2009.

[23] F. Abed, M. AlHamaydeh, and S. Abdalla, "Experimental and numerical investigations of the compressive behavior of concrete filled steel tubes (CFSTs)," Journal of Constructional Steel Research, vol. 80, pp. 429-439, 2013.

[24] M. H. Lai and J. C. M. Ho, "Behaviour of uni-axially loaded concrete-filled-steel-tube columns confined by external rings," The Structural Design of Tall and Special Buildings, vol. 23, no. 6, pp. 403-426, 2014.

[25] M. H. Lai, J. C. M. Ho, and H. J. Pam, "Experimental studies of spiral-confined HSCFST columns under uni-axial compression," World Academy of Science, Engineering and Technology, vol. 8, no. 6, pp. 571-577, 2014.

[26] Y. Wang, J. Chen, and Y. Geng, "Testing and analysis of axially loaded normal-strength recycled aggregate concrete filled steel tubular stub columns," Engineering Structures, vol. 86, pp. 192-212, 2015.

[27] L. Zhu, L. Ma, Y. Bai et al., "Large diameter concrete-filled high strength steel tubular stub columns under compression," Thin-Walled Structures, vol. 108, pp. 12-19, 2016.

[28] T. Ekmekyapar and B. J. M. Al-Eliwi, "Experimental behaviour of circular concrete filled steel tube columns and design 
specifications," Thin-Walled Structures, vol. 105, pp. 220-230, 2016.

[29] M.-X. Xiong, D.-X. Xiong, and J. Y. R. Liew, “Axial performance of short concrete filled steel tubes with high- and ultrahigh- strength materials," Engineering Structures, vol. 136, pp. 494-510, 2017.

[30] American National Standards Institute, ANSI/AISC 360-16: Specification for Structural Steel Buildings, American Institute of Steel Construction, Chicago, IL, USA, 2016.

[31] British Standard, Eurocode 4: Design of Composite Steel and Concrete Structures-Part 1-1: General Rules and Rules for Buildings, BSI, London, UK, 2009.

[32] Ministry of Housing and Urban-Rural Development of the People's Republic of China, GB 50936-2014: Technical Code for Concrete Filled Steel Tubular Structures, China Architecture \& Building Press, Beijing, China, 2014, in Chinese.

[33] G. Tang, Y. Xiao, and Y. Zhang, "Study of bearing capacity and complete stress-strain curves for concrete filled square steel tube columns," Engineering Mechanics, vol. 32, no. 8, pp. 103-110, 2015, in Chinese.

[34] L.-H. Han, G.-H. Yao, and Z. Tao, "Performance of concretefilled thin-walled steel tubes under pure torsion," Thin-Walled Structures, vol. 45, no. 1, pp. 24-36, 2007.

[35] J. Wang and Q. Sun, "Seismic behavior of Q690 circular HCFTST columns under constant axial loading and reversed cyclic lateral loading," Steel and Composite Structures, vol. 32, no. 2, pp. 199-212, 2019.

[36] L. H. Han, Concrete Filled Steel Tubular Structures-Theory and Practice, Science Press, Beijing, China, 2016, in Chinese, 3rd edition.

[37] F.-C. Wang, H.-Y. Zhao, and L.-H. Han, "Analytical behavior of concrete-filled aluminum tubular stub columns under axial compression," Thin-Walled Structures, vol. 140, pp. 21-30, 2019.

[38] Q. Q. Liang and S. Fragomeni, "Nonlinear analysis of circular concrete-filled steel tubular short columns under axial loading," Journal of Constructional Steel Research, vol. 65, no. 12, pp. 2186-2196, 2009.

[39] Z.-B. Wang, Z. Tao, L.-H. Han, B. Uy, D. Lam, and W.-H. Kang, "Strength, stiffness and ductility of concretefilled steel columns under axial compression," Engineering Structures, vol. 135, pp. 209-221, 2017.

[40] G. Giakoumelis and D. Lam, "Axial capacity of circular concrete-filled tube columns," Journal of Constructional Steel Research, vol. 60, no. 7, pp. 1049-1068, 2004.

[41] M. Yu, W. Zeng, and N. Lu, "New theory of engineering structural analysis and its application," Engineering $\mathrm{Me}$ chanics, vol. 11, no. 1, pp. 9-20, 1994, in Chinese.

[42] M. H. Yu and J. C. Li, Computational Plasticity: With Emphasis on the Application of the Unified Strength Theory, Springer Science \& Business Media, Berlin, Germany, 2012.

[43] J. Zhao, Q. Gu, and S. Ma, "The study of the axial compressive strength of concrete filled steel tube (CFST) based on the twin shear unified strength theory," Engineering Mechanics, vol. 19, no. 2, pp. 32-35, 2002, in Chinese.

[44] F. E. Richart, A. Brandtzæg, and R. L. Brown, A Study of the Failure of Concrete under Combined Compressive Stresses, University of Illinois at Urbana Champaign, Champaign, IL, USA, 1928.

[45] J. Wei, J. Zhao, Y. Liu, and H. Tian, “Analysis of ultimate bearing capacity of concrete-filled steel tubular axial compression short columns," Journal of Architecture and Civil Engineering, vol. 25, no. 3, pp. 81-86, 2008, in Chinese.
[46] S-T. Zhong, High-Rise Buildings of Concrete Filled Steel Tubular Structures, Heilongjiang Science and Technology Publishing House, Harbin, China, 1999, in Chinese.

[47] T. Yamamoto, J. Kawaguchi, and S. Morino, "Experimental study of scale effects on the compressive behavior of short concrete-filled steel tube columns," in Proceedings of the 4th Composite Construction in Steel and Concrete Conference, Banff, Canada, 2002. 